\title{
Does One Size Fit All? Modelling Macroeconomic Linkages in the West African Economic and Monetary Union
}

by

David Fielding*, Kevin Lee**, and Kalvinder Shields***

\begin{abstract}
We construct a structural macroeconometric model for member states of the West African Economic and Monetary Union (UEMOA). Fitting this model to annual and quarterly time-series data allows us to identify the channels through which macroeconomic innovations in one country impact on other countries in the union. We also discover the extent of heterogeneity across the member states in terms of the degree of similarity of macroeconomic transmission mechanisms. This is one important element in measuring the costs of union membership for each country.
\end{abstract}

JEL Classifications: F15, F33

Keywords: West African Monetary Union, Structural VAR.

${ }^{*}$ Department of Economics, University of Otago and WIDER, United Nations University, Helsinki.

** Department of Economics, University of Leicester, UK. ${ }^{* * *}$ Department of Economics, Melbourne University, Australia. Corresponding author: David Fielding, Department of Economics, University of Otago, Dunedin 9001, New Zealand. E-mail: dfielding@business.otago.ac.nz; telephone: ++64-3-4798653. Version dated January 2005. 


\section{Introduction}

Over the last forty years most economies in Sub-Saharan Africa have been characterised by exchange rate instability, financial fragility and high inflation. The continent as a whole is the furthest from achieving the UNDP's Millennium Development Goals, and seems to be diverging from rather than converging on the industrialized world (Easterly and Levine, 1997; World Bank, 2003). Many Sub-Saharan African countries are economically very small, and it is possible that one factor handicapping African economic development is the absence of opportunities to exploit economies of scale in production and trade. For this reason, the promotion of macroeconomic integration in Sub-Saharan Africa is, if anything, even more urgent than elsewhere in the world.

One possible route to greater macroeconomic integration is the formation of monetary unions. In fact, there is a part of Africa - the African Financial Community (CFA) - in which a monetary union has existed for over half a century. At present, the CFA comprises 14 different countries formed into two monetary unions, the West African Economic and Monetary Union (UEMOA) and the Central African Economic and Monetary Community (CEMAC). In each of these two areas there is a single currency and a single central bank setting its own interest rate and credit creation targets. These monetary unions trace their existence back to the monetary institutions of French colonial Africa. The two central banks (the BCEAO and the BEAC) date from 1955, seven years before the end of French rule, and most of the current member states have never had a national currency. The two CFA currencies were pegged against the French Franc at a fixed rate, until France adopted the Euro, the currency to which the CFA currencies are now pegged. There has been a single devaluation of the two currencies against the French Franc, in January 1994.

There is a body of evidence suggesting that membership of the CFA has generated substantial benefits for many of the member states in terms of monetary and financial stability and regional integration (Stasavage, 1997; Fielding and Shields, 2005). However, as is well known from Optimum Currency Area theory, there are also potential costs. If the countries experience heterogeneous macroeconomic shocks, the imposition of a single monetary policy will result in welfare losses relative to a world in which all countries 
have their own currency. Equally, if shocks (or indeed monetary policy responses) are transmitted in different ways in different countries, a single currency entails some cost. Identifying the structural linkages between the countries of a monetary union is essential in understanding the macroeconomic consequences of a single currency. While there are a few existing papers on macroeconomic shocks in the CFA (Hoffmaister et al., 1998; Fielding and Shields, 2001), these papers are based on VAR models containing just two or three aggregate variables with a limited identification structure; they are not designed to identify the structural linkages between CFA countries. Indeed, fully structural macroeconomic models are very rare in development economics, because there are few countries in which quarterly macroeconomic data are recorded over a long enough period for such modelling to be feasible.

Nevertheless, there are data for most of the members of the UEMOA that are adequate for such a task. In this paper, we will estimate a structural macroeconometric model of countries in the UEMOA, in order to explore how the different economies interact. There are two objectives to this exercise. First, we wish to understand in more detail how the different countries' economies within the UEMOA are interrelated, in order to inform monetary policy within the region. Second, we wish to develop a general macro-econometric framework for studying interactions within a monetary union that is of potential use in other regions, both in Africa and elsewhere.

The remainder of the paper is organised as follows. In Section 2, we develop a simple theoretical framework within which we can consider the relationships between macroeconomic aggregates within each country and the linkages between countries in the UEMOA. The framework focuses on the relationships that are likely to hold in the long-run for which there is a degree of consensus amongst economists. These relationships may only come about after some time, but they will exert an important influence on the dynamic responses of the system to innovations and it is essential that these influences are understood if the nature of shocks impacting on the economies is to be identified and if the dynamic response of the economies to these shocks is to be understood. In Section 3, we elaborate the econometric framework to be employed in building the analysis. This takes the form of a 'long-run structural Vector Autoregressive (VAR)' model in which 
the long-run relationships outlined in Section 2 are embedded within an otherwise unrestricted VAR model. The nature of the instantaneous and short-run relationships that exist between variables are dominated by rigidities of different kinds, and economic theory is typically agnostic on how these will impact in different parts of the macroeconomy and in different countries. These short-run relationships are nevertheless crucially important in understanding the nature of shocks and the system's dynamic response. The use of a VAR modelling framework enables us to capture the complicated dynamics that exist in the data without imposing contentious identifying structure on the short-run relationships. Section 4 describes the data and the estimated model for the UEMOA, and provides some insights on the dynamic properties of the model of UEMOA through an 'impulse response analysis'. Section 5 concludes.

\section{The Theoretical Framework}

In this section, we present the structure of the macroeconometric model through which we will characterise the long-run relationships that exist between macroeconomic variables within each country and the macroeconomic linkages that exist between each country in the UEMOA. There are several potential linkages that exist across countries in the long-run:

1. The UEMOA is a common currency area, so there will be a single demand curve for (narrow) money across the union. A positive shock to the nominal money stock is likely to generate inflation in all countries, although in the short run the extent of this inflation may vary, because of differences in the extent of price stickiness across countries. For example, if there is price inertia in country A, a nominal money shock may cause prices to overshoot in country B.

2. In the long run, the mobility of goods and factors within the monetary union is likely to guarantee at least weak Purchasing Power Parity across all the countries. Strong PPP might not hold because of heterogeneity in the local prices of non-traded goods, caused by differences in local supply and demand conditions. If factor relocation is costly, the resulting wedges between national consumer prices might persist in 
the steady state. But they certainly ought to be stationary since too large a wedge would stimulate equilibrating movements in factors of production. Therefore, the asymptotic effect of a shock to prices in country A is likely to be the same in all member states (including country A).

A caveat to this proposition is that the exchange rate devaluation in 1994 might have had an impact on relative prices across the members of the UEMOA. Standard openeconomy macroeconomic models show that, with imperfect substitutability between traded and non-traded goods, a devaluation can have a permanent impact on the real exchange rate. Non-traded goods prices can rise less than proportionately to the increase in traded goods prices. (See for example Fielding and Bleaney, 2000.) The size of the effect depends on elasticities of substitution, and on the share of non-traded goods in total consumption, which could vary across UEMOA members.

3. Until recently there were no effective constraints on individual governments' borrowing from the $\mathrm{BCEAO}$, but the $\mathrm{BCEAO}$ faces a binding external financing constraint in the form of the Operations Account. So in our data (ending in 2000) any binding long-run Balance of Payments condition is likely to apply to the UEMOA as a whole rather than to individual countries. When there is a shock to the trade balance of one country, for instance through an innovation in its terms of trade, adjustment of prices and output to maintain a long-run external balance is likely to be spread across all the members of the union.

4. The levels of aggregate demand in each country are likely to be linked in several ways. First, all the countries face common interest rates. Secondly, each country's price level, and therefore its real exchange rate, is likely to depend on events in other countries for the reasons outlined in (1)-(3) above. Thirdly, there is substantial labor mobility across the countries of the UEMOA, especially immigration into Côte d'Ivoire from its smaller neighbours, with correspondingly large remittances out of Côte d'Ivoire. This means that shocks to income in one economy, particularly in Côte d'Ivoire, are likely to have a direct impact on aggregate demand in at least some of the others. 
A complete model of the economies of the UEMOA requires the country-specific macroeconomic relationships that exist to be described in such a way that they can be integrated with each other to accommodate the important linkages listed above.

In what follows, we will estimate a 'long-run structural VAR' model that accommodates both the relationships that exist between the macroeconomic variables of the individual nations and the relationships that exist across the economies of the UEMOA. A 'long-run structural VAR' model has the advantage that it can capture the complex dynamic relationships that exist in the data and, at the same time, it can accommodate the structural relationships that exist between variables in the long run, as suggested by economic theory. Stated briefly, and in view of points (1)-(4) above, the long-run structural relationships include: (i) an aggregate LM curve for the whole monetary union; (ii) an aggregate $\mathrm{BP}$ curve for the whole monetary union; (iii) $n-1$ PPP equations linking prices in each of the $n$ countries; and (iv) $n$ IS curves, one for each country, describing the determination of country-specific aggregate demand. ${ }^{1}$ The interactions between economies are accommodated partly through the use of zone-wide relationships in (i) and (ii), and partly through the use of aggregate, zone-wide variables constructed on the basis of the corresponding variables measured at the level of the individual economies.

More specifically, our long-run structural model involves $4 n+4$ distinct variables. There are four zone-specific variables: the CFA Franc - French Franc exchange rate, $S_{t}$; the total money base issued in the countries, $M_{t}$; a common nominal interest rate faced by all countries, $R_{t}$; and a measure of world activity, $Y_{t}^{*}$. The remaining $4 n$ distinct variables consist of four variables measured for each country: real GDP in country $i, Y_{i t}$ $(i=1, . ., n)$; the consumer price index, $P_{i t}$, and the export price, $P_{i t}^{x}$, reflecting the price in CFA Francs of goods produced in country $i(i=1, . ., n)$, and consumed in country $i$ or exported abroad; and the import price index, $P_{i t}^{z *}$, reflecting the price in French Francs of goods produced abroad but imported to country $i(i=1, . ., n)$. In the work, we also make use of import volumes in each country $i, Z_{i t}(i=1, . ., n)$. Using lower case letters to denote

\footnotetext{
${ }^{1}$ There are no explicit aggregate supply relationships in the model. However the model is consistent with the existence of country-specific productivity shocks that impact on the country's output and on all other variables in the system through the relations embedded in the model.
} 
logarithms, so that $y_{i t}=\log \left(Y_{i t}\right)$ and so on, the zone-wide variables corresponding to the economy-wide variables are defined by their weighted geometric averages. Hence, zonewide output level is $y_{t}=\sum_{i} w_{i}^{y} y_{i t}$; the zone-wide price level is $p_{t}=\sum_{i} w_{i}^{y} p_{i t}$, the zone-wide export price is $p_{t}^{x}=\sum_{i} w_{i}^{z} p_{i t}^{x}$, and the zone-wide import price is $p_{t}^{z *}=\sum_{i} w_{i}^{z} p_{i t}^{z *}$. Countryspecific weights $\mathbf{w}^{y}=\left(w_{1}^{y}, . ., w_{n}^{y}\right)^{\prime}$ are based on the relative size of the country by output over the sample period (so that $w_{i}^{y}=\sum_{t} y_{i t} / \sum_{i} \sum_{t} y_{i t}$ ), while the $\mathbf{w}^{z}=\left(w_{1}^{z}, . ., w_{n}^{z}\right)^{\prime}$ are based on the relative size of the country by import activity (so that $w_{i}^{z}=\sum_{t} z_{i t} / \sum_{i} \sum_{t} z_{i t}$ ).

Using these definitions, and based on the economic relationships described in (i)-(iv) above, we have a model in which there are $2 n+1$ long-run relations of the form:

$$
\begin{gathered}
m_{t}-p_{t}=a_{0}(t)+a_{1} y_{t}-a_{2} R_{t}-a_{3} \Delta p_{t}+a_{4} s_{t}+\xi_{a t}, \\
e_{t}=b_{0}(t)+b_{1} y_{t}+b_{2}\left(p_{t}-p_{t}^{x}\right)+b_{3} y_{t}^{*}+b_{4} s_{t}+\xi_{b t} \\
p_{i t}=c_{i 0}(t)+p_{t}+c_{i 1} s_{t}+\xi_{c i t}, \quad i=1, \ldots, n-1,
\end{gathered}
$$

and

$$
y_{i t}=d_{i 0}(t)+d_{i 1} e_{i t}-d_{i 2}\left(R_{t}-\Delta p_{i t}\right)+d_{i 3} y_{t}^{*}+\xi_{d i t} \quad i=1, \ldots, n,
$$

where $e_{i t}=s_{t}+p_{i t}^{z *}-p_{i t}$ are the national real exchange rates and $e_{t}=s_{t}+\sum_{i} w_{i}^{z}\left(p_{i t}^{z *}-p_{i t}\right)$ is the aggregate analogue. If we take $R_{t}, s_{t}, y_{t}^{*}, p_{i t}^{x}$ and $p_{i t}^{z *}$ as exogenous, which is reasonable, then there are $2 n+1$ equations in (1)-(4) explaining the long-run determination of $2 n+1$ endogenous variables; namely $m_{t}$, the $y_{i t}(i=1, . . n)$, and the $p_{i t}(i=1, . ., n)$. Hence, we have an exactly identified system in the long run.

Equation (1) describes the long-run LM curve for the whole monetary union, with the demand for real money balances influenced by zone-wide activity and interest rates. Equation (2) reflects the binding Balance of Payments condition faced at the union-level, with the aggregate real exchange rate adjusting in the face of zone-level activity, terms of trade and world trade. The $n-1$ relations of (3) reflect the weak Purchasing Power Parity that will hold across the nations in the long-run. In all of these cases, we allow for the possibility that the devaluation had a permanent impact on the relations through the inclusion of $s_{t}$ as a separate variable in the first three equations. (This is effectively a dummy variable, as the exchange rate changed only once in the sample period.) Finally, 
the $n$ relations of (4) describe product market equilibrium in each of the individual nations, with aggregate demand influenced by the country-specific real exchange rate, real interest rates (defined with reference to the country's own inflation rate), and levels of world trade. $^{2}$

Identification of the deterministic components of the equations in (1)-(4), i.e. $a_{0}(t)$, $b_{0}(t)$, etc., will be based on empirical information criteria. We expect all other parameters to be positive. The terms $\xi_{a t}, \xi_{b t}, \boldsymbol{\xi}_{c t}=\left(\xi_{c 1 t}, . ., \xi_{c, n-1, t}\right)^{\prime}$, and $\boldsymbol{\xi}_{d t}=\left(\xi_{d 1 t}, . ., \xi_{d n t}\right)^{\prime}$ are $2 n+1$ stationary errors which represent deviations from equilibria in each of the long-run relations. The errors may have substantial serial correlation, indicating that disequilibria may last for protracted periods in different markets. But the fact that they are stationary reflects the view that the disequilibria will vanish in the long run.

\section{The Econometric Framework}

The theoretical model described above concentrated on the long-run relationships that might exist among the macroeconomic variables of a country and between the various countries of UEMOA. In this section, we note how these long-run relationships can be embedded within a coherent VAR framework that can also capture the complicated shortrun dynamic relations between the countries' variables. The modelling strategy employed has been recently developed, and is explained in detail, in Garratt et al (2003).

A coherent VAR model of UEMOA incorporating the relations of (1)-(4) can be constructed by stacking together the $4 n+3$ distinct variables of interest in a single vector of variables, $\mathbf{z}_{t}$, where

$$
\mathbf{z}_{t}=\left(R_{t}, s_{t}, y_{t}^{*}, \mathbf{p}_{t}^{x \prime}, \mathbf{p}_{t}^{z^{* \prime}}, m_{t}, \mathbf{y}_{t}^{\prime}, \mathbf{p}_{t}^{\prime}\right)^{\prime}
$$

and $\mathbf{p}_{t}^{z^{*}}=\left(p_{1 t}^{z^{*}}, . ., p_{n t}^{z^{*}}\right)^{\prime}, \mathbf{p}_{t}^{x}=\left(p_{1 t}^{x}, . ., p_{n t}^{x}\right)^{\prime}, \mathbf{y}_{t}=\left(y_{1 t}, . ., y_{n t}\right)^{\prime}$ and $\mathbf{p}_{t}=\left(p_{1 t}, . ., p_{n t}\right)^{\prime}$. Next note that the vector of long-run structural disturbances $\boldsymbol{\xi}_{t}=\left(\xi_{a t}, \xi_{b t}, \boldsymbol{\xi}_{c t}^{\prime}, \boldsymbol{\xi}_{d t}^{\prime}\right)^{\prime}$, containing the disequilibria from the long-run relations in (1)-(4), can be written as a linear combination of the variables in $\mathbf{z}_{t}$ :

$$
\boldsymbol{\xi}_{t}=\boldsymbol{\beta}^{\prime} \mathbf{z}_{t}-\mathbf{b}(t)-\boldsymbol{\delta} \Delta \mathbf{z}_{t}
$$

\footnotetext{
${ }^{2}$ The justification for the use of a common interest rate in the countries' IS relations is provided below.
} 
for an appropriate deterministic vector $\mathbf{b}(t)$ and with $\boldsymbol{\beta}^{\prime}$ and $\boldsymbol{\delta}$ both being $(2 n+1) \times(4 n+4)$ matrices of the form

$$
\boldsymbol{\beta}^{\prime}=\left(\begin{array}{cccccccc}
a_{2} & 0 & 0 & \mathbf{0} & \mathbf{0} & 1 & -a_{1} \mathbf{w}^{y^{\prime}} & -\mathbf{w}^{y \prime} \\
0 & 1 & -b_{3} & b_{2} \mathbf{w}^{z \prime} & \mathbf{w}^{z \prime} & 0 & -b_{1} \mathbf{w}^{y^{\prime}} & -\left(1+b_{2}\right) \mathbf{w}^{z \prime} \\
\mathbf{0} & \mathbf{0} & 0 & \mathbf{0} & \mathbf{0} & \mathbf{0} & \mathbf{0} & \boldsymbol{\Theta}_{1}^{\prime} \\
\mathbf{d}_{2} & -\mathbf{d}_{1} & -\mathbf{d}_{3} & \mathbf{0} & -\mathbf{d}_{1} \mathbf{w}^{z \prime} & \mathbf{0} & \mathbf{I}_{n} & \mathbf{d}_{1} \mathbf{w}^{z \prime}
\end{array}\right)
$$

and

$$
\boldsymbol{\delta}=\left(\begin{array}{cccccccc}
0 & 0 & 0 & \mathbf{0} & \mathbf{0} & 0 & \mathbf{0} & a_{3} \mathbf{w}^{y} \\
0 & 0 & 0 & \mathbf{0} & \mathbf{0} & \mathbf{0} & \mathbf{0} & \mathbf{0} \\
\mathbf{0} & \mathbf{0} & \mathbf{0} & \mathbf{0} & \mathbf{0} & \mathbf{0} & \mathbf{0} & \mathbf{0} \\
\mathbf{0} & \mathbf{0} & \mathbf{0} & \mathbf{0} & \mathbf{0} & \mathbf{0} & \mathbf{0} & -\mathbf{d}_{2} \mathbf{w}^{y \prime}
\end{array}\right)
$$

where $\boldsymbol{\Theta}_{1}$ is the first $n-1$ rows of $\mathbf{w}-\mathbf{w}^{y}$, where $\mathbf{w}$ is an $n$-vector of ones, where $\mathbf{d}_{1}, \mathbf{d}_{2}$ and $\mathbf{d}_{3}$ are $n$-vectors containing the parameters $d_{i 1}, d_{i 2}$ and $d_{i 3}, i=1, . ., n$, respectively. The final step in the modelling strategy is to embed the structural disturbances, $\boldsymbol{\xi}_{t-1}$, in a $\operatorname{VAR}(\mathrm{s}-1)$ model in $\Delta \mathbf{z}_{t}$ :

$$
\Delta \mathbf{z}_{t}=\overline{\mathbf{a}}(t)-\boldsymbol{\alpha} \boldsymbol{\xi}_{t-1}+\sum_{i=1}^{s-1} \overline{\boldsymbol{\Gamma}}_{i} \Delta \mathbf{z}_{t-i}+\mathbf{v}_{t}
$$

where, given the assumption that $R_{t}, s_{t}, y_{t}^{*}, p_{i t}^{x}$ and $p_{i t}^{z^{*}}$ are determined exogenously, $\boldsymbol{\alpha}$ will be of the form $\boldsymbol{\alpha}=\left(\boldsymbol{\alpha}_{e x}^{\prime}, \boldsymbol{\alpha}_{e n}^{\prime}\right)^{\prime}$ with $\boldsymbol{\alpha}_{e x}$ a $(2 n+3) \times(2 n+1)$ matrix of zeros. In view of $(5),(7)$ can be written equivalently as

$$
\Delta \mathbf{z}_{t}=\mathbf{a}(t)-\boldsymbol{\alpha} \boldsymbol{\beta}^{\prime} \mathbf{z}_{t-1}+\sum_{i=1}^{s-1} \boldsymbol{\Gamma}_{i} \Delta \mathbf{z}_{t-i}+\mathbf{v}_{t}
$$

where $\mathbf{a}(t)=\overline{\mathbf{a}}(t)-\boldsymbol{\alpha} \mathbf{b}(t), \boldsymbol{\Gamma}_{1}=\overline{\boldsymbol{\Gamma}}_{1}-\boldsymbol{\alpha} \boldsymbol{\delta} \boldsymbol{\Delta} \mathbf{z}_{\mathbf{t}}, \boldsymbol{\Gamma}_{i}=\overline{\boldsymbol{\Gamma}}_{i}, i=2, . ., s-1$. This is, of course, the familiar vector error correction (VECM) form. The form of the model allows for the presence of complex dynamic relationships between the variables of the system and it is a convenient parameterisation of the system because it highlights the role of the long-run relationships that exist between the levels of the variables in influencing these dynamics. In the case where the variables in $\mathbf{z}_{t}$ are stationary in differences, the stationarity of the structural disturbances $\boldsymbol{\xi}_{t-1}$ means that the $\boldsymbol{\beta}$ vector describes the linear combination of the variables in $\mathbf{z}_{t-1}$ which are stationary; i.e. the cointegrating 
vectors. In this case, the modelling strategy leads us to estimate a cointegrating VAR model, but the route taken ensures that the long-run relationships suggested by economic theory are explicitly embedded within the model (through the explicit restricted form of (6)). This contrasts with the more usual approach found in the literature in which an unrestricted cointegrating VAR is estimated first and then an investigation of the nature of long-run relations is undertaken.

\section{A Structural VAR Model of UEMOA}

\subsection{Data description}

A model of the UEMOA that can be used to investigate the nature of the shocks impacting on the zone and their dynamic effects requires quarterly data (at least). For the majority of the variables under consideration, data is readily available at quarterly frequency in the IMF International Financial Statistics. But the shortage of quarterly National Accounts data means that there are no official GDP statistics reported on a quarterly basis. However, it is possible for some of the countries to interpolate quarterly series from the annual GDP data using quarterly figures for electricity consumption. In other words, we construct the GDP for quarter $q$ in year $t$ as:

$$
Y_{q t}=\frac{H_{q t}}{H_{t}} Y_{t}
$$

where $Y_{t}$ is GDP in year $t, H_{t}$ is electricity consumption in year $t$ and $H_{q t}$ is electricity consumption in quarter $q$ of year $t$. (This approximation is based on the assumption that electricity consumption is proportional to the supply of services, manufacturing production and the storage and distribution of agricultural produce. Some measurement error may arise because of sectoral variation in the share of electricity in total factor inputs, but note that aggregate output is a dependent variable in our model, so we implicitly allow for measurement error in $Y_{t}$.) Annual GDP figures are reported in the World Bank World Development Indicators and quarterly electricity consumption in the BCEAO Notes d'Information et Statistiques. However, this is possible for only five of the members of the UEMOA: Burkina Faso, Mali, Senegal, Togo and Côte d'Ivoire. It is not possible for Benin, Guinea-Bissau and Niger. For this reason, the empirical analysis will be limited 
to the first five countries (i.e. $n=5$ ), although this is reasonable given that these five countries make up over $90 \%$ of the GDP of the UEMOA.

A second practical difficulty in constructing the model arises in the measurement of interest rates where there are also serious data limitations. The only UEMOA rate reported consistently for any length of time is the BCEAO rediscount rate, which changes seldom. In the long run, the rediscount rate appears to conform to an interest parity condition with the equivalent French rate (see Appendix 1), but there are periods during which it is fixed for years at a time. ${ }^{3}$ For this reason we will rely on a French interest rate to capture the opportunity cost of loanable funds. We define the nominal interest rate $R_{t}$ as the French government bond yield, and construct the real interest rate terms in the IS curves using national inflation rates. Implicitly, we will rely on a substantial degree of capital market integration between the UEMOA and France, so that the (unobserved) opportunity cost of loanable funds in the UEMOA tracks the French interest rate. The fact that, in the long run, there appears to be interest parity even with respect to the very sticky BCEAO rediscount rate suggests that this is a reasonable assumption.

One limitation of our data is that it has not been possible to interpolate quarterly GDP figures for years prior to 1987. This means our first observation is for 1987q1 and the quarterly data set is for 1987q1-2000q4 (56 observations). This is a rather short time period on which to estimate the long-run restrictions in equations (1)-(4). Annual data are available for longer (1970-2000), but 31 annual observations would not be enough to be confident that we have a robust estimate of the structural VAR. In any case, the interpretation of the fitted model in terms of the response of the economies to shocks really requires data at a quarterly frequency. For this reason, we will estimate our model using both annual and quarterly data in a two-step procedure. In the first step, the long-run relations in equations (1)-(4) will be estimated using the annual data using single-equation estimation techniques. The estimated long-run relations will then be used to construct corresponding disequilibrium measures at the quarterly frequency and, in the second step of the procedure, these disequilibrium terms will be used in the estimation of a structural

\footnotetext{
${ }^{3}$ Indeed, one finds empirically that, when the BCEAO rediscount rate is included in a structural VAR model, it exhibits no significant relationship with any other macroeconomic variable.
} 
model of the form in (8) using our quarterly data.

The estimation of the model in two stages represents a pragmatic procedure to overcome the modelling difficulties arising from the limitations of the data and to best exploit the data that is available. As we emphasise when we estimate the quarterly version of the model in the second stage, there are complex interactions and feedbacks that exist across the various sectors of the macroeconomy which can only be captured adequately by a full system-wide estimation procedure. Such an exercise is very data intensive, however, and beyond what is possible using the short run of quarterly data that is available. The first stage of the estimation uses single-equation techniques that are misspecified in the sense that they cannot capture all of the feedbacks involved in the full system. But these equations will be able to provide consistent estimates of the long-run relationships and exploit the longer sample period covered by the annual data. Having obtained these long-run relationships, they can be embedded within a well-specified model of the entire system that can help identify the shocks impacting on the economy and the detailed dynamic responses of the macroeconomic aggregates using the available quarterly data.

\subsection{Estimating the long-run relationships}

The first stage of the estimation considers each of the long-run relationships in (1)-(4) separately using annual data. The analysis of long-run relations among economic series typically requires judgement to be made on whether the series are stationary in levels, $I(0)$, or stationary in differences, $I(1)$. However, in small samples of the type that we face, it is not possible to determine with any confidence the order of integration of the time series of interest. Typically, one can reject neither the hypothesis that a variable is $I(1)$ nor the hypothesis that it is $I(0)$.

For this reason, the long-run relationships in equations (1)-(4) are estimated using the single-equation estimation method of Pesaran, Smith and Shin (2001) [PSS] which does not require knowledge of the order of integration of the series under consideration (although all of the variables involved are assumed either $I(0)$ or $I(1)$ ). Taking each of the relationships in (1)-(4) in turn, this method involves treating the LHS variable as a dependent variable and fitting an autoregressive distributed lag (ARDL) model of the 
variable using the available annual data on the variables appearing in the relationship. The PSS test involves a parameterisation of the ARDL specification in which the difference of the dependent variable is regressed on the contemporaneous differences of the other variables involved, on upto $s$ lags of its own difference and of the differences of the other variables, and on the first lag of the levels of all the variables involved. Underlying the modelling approach is the assumption that there exists only one long-run relationship among the variables under consideration (as is the case here when each of the relationships in (1)-(4) are considered in turn). The test of the existence of a long-run relationship among the variables is based on the F-statistic calculated to test the joint significance of the parameters on the lagged levels terms which is compared with the critical values provided in PSS.

Hence, for example, in investigating the presence of the long-run IS curve of (4) for country $i$, we regress the difference of $y_{i t}$ on the contemporaneous differences in $e_{t},\left(R_{t}-\right.$ $\left.\Delta p_{i t}\right)$ and $y_{t}^{*}$, on one lag of these differences, plus the lagged levels $y_{i, t-1}, e_{t-1},\left(R_{t-1}-\right.$ $\left.\Delta p_{i, t-1}\right)$ and $y_{t-1}^{*}$. The choice of one lag was made on the basis of the Schwarz-Bayesian information criterion. A specification search is undertaken to improve the parsimony of the equation, so that a variable in differences on the RHS is dropped if it is statistically insignificant (i.e. it's associated t-value is less than unity in absolute terms). The test of the joint insignificance of the levels of $y_{i, t-1}, e_{t-1},\left(R_{t-1}-\Delta p_{i, t-1}\right)$ and $y_{t-1}^{*}$ then provides a test of the existence of the hypothesised long-run IS relationship.

Tables 1a-c report the results of estimating the ARDL models corresponding to the $2 n+1=11$ relationships in (1)-(4) using the annual data available over 1972-2000 for Burkina Faso, Mali, Senegal, Togo and Côte d'Ivoire. As we discuss in detail below, the estimated models are interesting in their own right: the equations perform well in terms of their statistical properties, and the size and magnitude of the estimated longrun elasticities are sensible economically. But importantly, in terms of our two-stage procedure, the regressions also provide evidence of the existence in the data of the longrun equilibrium relationships suggested at (1)-(4). The following table summarises the $\mathrm{F}_{B O U N D S}$ test of the joint insignificance of the lagged levels terms in each of the 11 
relationships presented in Table 1:

\begin{tabular}{|c|c|c|c|c|c|c|c|c|c|c|c|}
\hline & \multicolumn{10}{|c|}{ Dependent Variable: } \\
\hline & $\Delta\left(m_{t}-p_{t}\right)$ & $\Delta e_{t}$ & $\Delta p_{1 t}$ & $\Delta p_{2 t}$ & $\Delta p_{3 t}$ & $\Delta p_{4 t}$ & $\Delta y_{1 t}$ & $\Delta y_{2 t}$ & $\Delta y_{3 t}$ & $\Delta y_{4 t}$ & $\Delta y_{5 t}$ \\
$\mathrm{~F}_{\text {BOUNDS }}$ & 6.44 & 4.53 & 5.24 & 6.16 & 6.18 & 5.25 & 4.53 & 4.54 & 3.61 & 8.81 & 7.57 \\
\hline
\end{tabular}

The appropriate critical values for the tests on the PPP relationships, in which there is no time trend present, are provided in PSS Table C1(iv), while the critical values for the other relationships are provided in Table $\mathrm{C} 1$ (iii). In every case, the $\mathrm{F}_{B O U N D S}$ test statistic presented above lies above the corresponding upper bound critical value, indicating that the null (that there is no long-run relationship among the levels series) is rejected. ${ }^{4}$

Turning to the relationships themselves, Table 1a shows the regression corresponding to the zone-wide LM and BP relationships (equations (1) and (2)). In both cases, the relationships incorporate a time trend and one lag of the differences on the basis of the Schwarz-Bayesian Criteria calculated across specifications of varying lag length, including and excluding the trend. The specification searches employed to simplify the dynamics result in only minor simplifications, confirming the view that the dynamics underlying the relationships are relatively complex. The reported diagnostic statistics indicate that the regressions fit the data well and that there are no problems with the short-run restrictions imposed, or with residual serial correlation, functional form, normality or homoscedasticity.

Normalising on the lagged level of $m_{t}-p_{t}$ in the LM relationship, the long-run income elasticity of money demand is 2.48 , while the long-run interest elasticity is -1.41 . These estimates are larger than the income and interest elasticities of demand for narrow money estimated in some other African countries (see for example Adam, 1992), but they are consistent with standard economic theory. Normalising on $e_{t}$ in the BP relationship, we find coefficients on $y_{t},\left(p_{t}-p_{t}^{x}\right)$ and $y_{t}^{*}$ equal to $1.14,0.06$ and -0.01 , respectively. Since an increase in $e_{t}$ represents an increase in domestic competitiveness and an improved Balance of Payments, while an increase in $y_{t}$ and a decrease in $y_{t}^{*}$ will raise import demand and worsen the Balance of Payments, these long-run relationships between $e_{t}$ and $y_{t}$ and $y_{t}^{*}$ are

\footnotetext{
${ }^{4}$ The hypothesis is rejected at the $5 \%$ level in every case except the IS relationship for Senegal, where the test is significant at the $10 \%$ level.
} 
as predicted by theory. The coefficients on the trend and $s_{t}$ in the BP relationship indicate that, ceteris paribus, $e_{t}$ has been declining at approximately $3.9 \%$ per annum but that the devaluation of the nominal exchange rate by 100\% in 1994 caused a once-and-for-all rise in $e_{t}$ of $37.8 \%$, implying a $62.2 \%$ exchange rate pass-through into domestic prices.

Table $1 \mathrm{~b}$ provides the results of estimating the ARDL models for the PPP relationships of (3). Four PPP regression equations are reported and, arbitrarily, the country for which the regression equation is not estimated is Cote d'Ivoire. This choice makes no difference to the conclusions we draw from the equations. No role was found for a time trend in these equations, although the devaluation dummy shows in all four equations, reflecting the percentage increase or decrease in equilibrium prices in the country, relative to the UEMOA average, that followed from the devaluation (and indicating that the impact of the devaluation on domestic prices varied across the monetary union). The specification search provides support for more exclusion restrictions on the difference terms in these equations (as confirmed by the test statistics denoted $\chi_{L M}^{2}$ ) and the reported diagnostics are acceptable also. The additional diagnostic statistic reported in Table $1 \mathrm{~b}, \chi_{L M+}^{2}$, reports the outcome of the joint test of the exclusion restrictions plus the additional restriction that the coefficient on the $p_{i, t-1}$ is equal and opposite in sign to that on $p_{t-1}$, as required by the PPP assumption. In three of the four cases, this test statistic remains insignificant at the $5 \%$ level, but there is a marked increase over the $\chi_{L M}^{2}$ statistics in each case even though the coefficients appear similar in the results reported in the Table. These results reflect the ambiguity found in much of the literature investigating the PPP relationship but we consider the results to be sufficiently supportive of the PPP result that we shall proceed under this assumption in what follows.

Table 1c reports the estimation results for the IS curves. These curves show a number of common features. In all five cases, there is a negative relationship between $y_{t}$ and $R_{t}$ : in other words, the IS curves are downward-sloping in the conventional way. However, the slopes of the curves do vary substantially. Normalizing on $y_{t}$, the long-run interest rate coefficients vary between -0.18 (Burkina Faso) and -0.43 (Côte d'Ivoire). In four out of five cases, there is also a positive relationship between $y_{t}$ and $e_{t}$, the natural interpretation of which is that greater price competitiveness (higher $e_{t}$ ) boosts aggregate demand. The 
long-run real exchange rate coefficients vary between +0.26 (Côte d'Ivoire) and +0.10 (Burkina Faso), and the long-run world trade coefficients from -0.02 (Mali) to +0.24 (Togo). ${ }^{5}$. Finally, Table $1 \mathrm{c}$ shows that an increase in world trade has a direct positive impact on aggregate demand in two of the countries, namely, Côte d'Ivoire and Togo. There is no such effect in the remaining three countries, Burkina Faso, Mali and Senegal, where the long-run world trade coefficients take negative values close to zero.

\subsection{The VECM model}

We have seen that there is some heterogeneity in the structure of the long-run relationships between real macroeconomic variables in our five countries. However, in order to get a feel for the quantitative importance of the different parameters (and for whether there is a degree of heterogeneity that might justify a particular country to question it's membership of the UEMOA), we need to look at the dynamic properties of the model. So, in the second stage of the estimation procedure, we combine the information gleaned above with quarterly data, in order to determine how much heterogeneity there is in the macroeconomy, and the extent to which shocks in one part of the monetary union are transmitted elsewhere.

Table 2a-d provides the complete details of the model of the UEMOA taking account of the interdependencies and interactions across variables and across countries based on the quarterly data available for Burkina Faso, Mali, Senegal, Togo and Côte d'Ivoire over the period 1988q4-2000q4. Tables 2a, b and c provide the regression equations explaining the changes in the eleven endogenous variables of the system (namely, $m_{t}, p_{i t}, i=1, . ., 5$, and $\left.y_{i t}, i=1, . ., 5\right)$, while Table $2 \mathrm{~d}$ provides the results of regressions explaining the dynamics of the 'long-run forcing', exogenous variables (namely, $R_{t}, y_{t}^{*}, p_{t}^{x}$ and $p_{i t}^{z^{*}}, i=1, \ldots, 5$ ). Both sets of regressions are required for the purpose of identifying shocks to the endogenous

\footnotetext{
${ }^{5}$ In Togo, the long-run real exchange rate coefficient has the opposite sign. One limitation of our import price data is that we cannot distinguish between the prices of imports of consumer goods from those of capital and intermediate goods. If the latter are a large component of total imports then an increase in $e_{t}$ reflects an increase in production costs, relative to aggregate prices. Such an increase might depress investment demand, and this might explain the unexpected real exchange rate effect in Togo.
} 
variables and for investigating the dynamic responses of the endogenous variables to these shocks and to changes in the endogenous variables.

The reported results are the outcome of a specification search procedure that aims to capture all of the important interdependencies between variables and the complexity of the dynamics as parsimoniously as possible. To this end, for each of endogenously determined variables considered in the model, we estimated error correction specifications including the relevant first lag of disequilibrium terms, up to four lags of the differences of relevant endogenous variables and (current and lagged) difference of exogenous variables. (The reported regression equations are parsimonious modifications of an unrestricted VECM, in which some individual regression parameters have been restricted to zero.) Hence, in Table 2a for example, the general specification for the money growth equation for the zone incorporates the two zone-wide disequilibrium terms, $\widehat{\xi}_{L M, t-1}$ and $\widehat{\xi}_{B P, t-1}$, derived on the basis of the annual regressions presented in Table 1a. Also included are lagged changes in $m_{t}, y_{t}$, and $p_{t}$, and current and lagged values of $R_{t}, e_{t},\left(p_{t}-p_{t}^{x}\right)$ and $y_{t}^{*}$. Nine variables are dropped on the grounds of statistical insignificance (and the reported $\chi_{L M}^{2}$ statistic shows that these joint restrictions do not violate the data). The resulting equation accommodates complicated dynamics, including (weak) feedback from the money market (LM) disequilibrium term, and has sensible statistical properties according to the reported diagnostics.

Similar comments can be made on the remaining error correction regression models of Table $2 \mathrm{~b}$ and $2 \mathrm{c}$. In the price inflation and output growth equations for each country, the general specification includes the zone-wide LM and BP disequilibria, the country's IS disequilibrium and all of the separate countries' PPP disequilibria (reflecting the idea that there is the potential for arbitrage across each pair of countries). As in Table 2a, the diagnostic statistics confirm that the specifications that are obtained are, by-andlarge, consistent with the data. Complicated dynamic relationships are also observed, both through the inclusion of statistically significant lagged differences but also through the presence of two, three or sometimes four of the disequilibrium terms in each of the individual error correction regressions. The complexity of the dynamics is even more apparent when one considers the system as a whole, as set out in the form in (8). It is not 
possible to give an economically intuitive interpretation of the individual coefficients of the separate error correction regressions, in terms of their contribution to the overall system dynamics. For this reason, we turn now to the calculation of persistence profiles and generalised impulse responses, which provide simple summary indicators of the system's overall dynamics.

\subsection{The Dynamic Properties of the Model}

Figure 1 provides plots of the persistence profile associated with the system of equations reported in Table 2. The profiles trace out the effect of a 'typical' shock to the system of equations on the eleven disequilibrium terms. The shock is 'typical' in the sense that it reflects the covariances that are observed across shocks to the different equations in the system in the data. The profiles demonstrate the speed of convergence to the longrun equilibrium following such a shock, with the profiles scaled to take the unit value on impact and falling to zero in the long-run. They provide a very clear indication of the inertias and rigidities that exist in the various markets in the different countries as reflected in the estimated error correction regressions.

One clear observation is the great length time it takes for the BP relationship to reach equilibrium (Figure 1b). The adjustment process is non-monotonic, and after an initial convergence period in the wake of shock to BP there is a prolonged period of divergence, which last for over 60 quarters. One explanation for this inertia is the fixed peg of the nominal exchange rate to the Euro: adjustment to equilibrium must be achieved through movements in prices, or in money and output. So, although there is a long-run BP relationship, a shock causing a divergence from equilibrium will persist for longer than the time horizon of any real-world policy-maker. In other words, the timely correction of large aggregate BP disequilibria can only be achieved by nominal devaluations. From the point of view of the monetary union in aggregate (if not that of individual countries), external imbalances can persist for a considerable length of time.

Figures 1c-1g plot the PPP profiles. Despite the existence of the PPP condition, so that each profile returns to zero eventually, each of the plots exhibits a different speed of 
adjustment to equilibrium. It is useful to calculate a simple indicator of the magnitude of differences in the profiles. We do this by constructing a descriptive statistic that indicates the sum of the persistence measures at each time horizon $n$ multiplied by the respective $n$-th. For $n=1,2, . .40$, this statistic takes values of 452.14, 107.22, 165.85, 617.76 and 12.47 for the PPP relationships for Burkina Faso, Cote d'Ivoire, Mali, Senegal and Togo, respectively. In the cases of Cote d'Ivoire and Mali, the profiles fall close to zero within the first eight to ten quarters, but in the case of Burkina Faso, and especially in the case of Senegal, the profiles diverge from zero for much longer. This results is consistent with other empirical evidence (e.g. GLPS 2003) and reflects the view, accepted by many, that arbitrage through international trade will result in PPP only after many periods. Perhaps more interesting here, though, is the observation that there are considerable differences in the speed with which the PPP relationships are re-established for different countries. This reflects the fact that, even though PPP is established across all countries in the long run, there are significant periods of time during which some countries are out of equilibrium, either over- or under-pricing their output relative to the long-run position. While there is long-run price neutrality, these differential speeds of nominal adjustments across the countries can have substantial real effects over a short run; so, if there is a shock that causes a substantial initial deviation from PPP, the effects of this are likely to remain for a long time. However, we have yet to see whether such shocks are likely to be caused by a typical monetary innovation.

Looking at convergence to equilibrium in the goods markets (captured by Figures 1g$1 \mathrm{k}$ ), we again observe different patterns of behavior in different countries. If we construct summary statistics for output adjustment in the same form as those for prices adjustment discussed above, we arrive at the following values: 104.42 for Burkina Faso, 104.28 for Mali, 259.71 for Senegal, 374.89 for Togo and 3.50 for Cote d'Ivoire. The statistics reflect extremely rapid convergence in the case Cote d'Ivoire (within two to three quarters); but at the other extreme Senegal and Togo exhibit much slower convergence.

Finally, Figure 1a shows the convergence to equilibrium of the money market (LM) relationship. The profile falls rapidly after two to three quarters, but then evolves slowly to zero over the next thirty quarters. This pattern corresponds to a summation statistic 
of 293.98 .

Figure 2 presents the dynamic properties of the system in a slightly different way, by focussing on the impact of a certain kind of shock. Here we present the Generalised Impulse Response (GIR) analyses of the eleven endogenous variables to a shock to the interest rate equation. The GIR analysis is invariant to the order of the shock and shows the effect of a shock to a particular equation, taking into account the shocks to other equations in the system that are 'typically' observed in the data. The GIR offers a clearly defined illustration of the dynamic response of the system to a particular type of shock, but in many applications it is difficult to arrive at an economic interpretation of this sort of shock. In our case, however, the interest rate is exogenously determined. So the shock to the interest rate equation can be taken to be independent of the other shocks to the system, and can be interpreted as a monetary policy shock. ${ }^{6}$

In interpreting the GIRs, the first point to note is that in our model, the transmission mechanism for an interest rate shock is rather different from that in the typical OECD country. In our system, the interest rate is strictly exogenous, and the nominal exchange rate is fixed. A rise in the interest rate entails a fall in aggregate demand throughout the monetary union, as indicated by the IS curves. This creates a Balance of Payments surplus, which necessitates a real exchange rate appreciation. This appreciation can be achieved only through domestic inflation, so a higher interest rate is associated with higher prices, and the price impulse response profiles generally lie above the zero line. In fact, the dynamics of the model mean that a positive interest rate shock leads to fractionally lower prices in the short run in two out of the five countries (Burkina Faso and Togo), and the impulse response profiles for prices do exhibit some heterogeneity for the first twenty quarters after the shock (figures $2 \mathrm{~g}-2 \mathrm{k}$ ). This is in part a reflection in the heterogeneity of the PPP profiles in figure 1. However, figure 2 also indicates that the long-run price responses are relatively small, with a 1 percentage point interest rate shock leading to

\footnotetext{
${ }^{6}$ One can think of the exogeneity assumption as placing the interest rate variable first in the vector of variables (so that the interest rate influences the variables that follow it contemporaneously, but is not influenced by them). In this case, the GIR is the same as the Orthogonalised Impulse Responses, associated with Sims (1980), that are more typically reported.
} 
a positive price deviations of just lower than half a percent. Changes in the interest rate do not have a quantitatively significant impact on prices. This result is consistent with the observation in previous work that typical deviations from PPP in most UEMOA countries are not that large. The dynamics of the macroeconomic model that represents the UEMOA contain the potential for substantial persistence in deviations from PPP, but (monetary) shocks causing a large initial deviation are unlikely to be common.

Output also falls in all of the countries following the interest rate shock, and by a quantitatively significant amount. Interestingly - since this is not a feature imposed by the structure of the model - output levels recover to close to the levels that they would have achieved in the absence of the shock after 2-3 years in these countries, indicating that while monetary policy has an impact in the short run, there is long-run neutrality. Nevertheless, there is some short-run heterogeneity in the response profiles, so a typical (monetary) policy shock is likely to cause divergent output responses in the short run. This greater divergence in output responses than in price responses is a feature common to previous papers, based on annual data and less detailed macroeconomic models, for example Fielding et al. (2003).

\section{Concluding Comments}

The paper develops and applies a novel modelling framework for the countries of the UEMOA. The framework has a coherent economic foundation, capturing economicallymeaningful relationships that exist across variables within a country and across countries in a monetary union in the long-run. But it is able to capture the complex short-run dynamic interactions involved in the determination of these variables too, allowing us to identify economically meaningful shocks to exogenous variables and to trace out the effects of these (and indeed any other) shocks on the system through impulse response analysis.

An important determinant of the net benefit of membership of a monetary union is the extent to which the countries' responses to shocks are similar. The impulse responses provided in the previous section indicate that there are considerable differences in the dynamic responses of the countries to shocks (in terms of the speed with which each 
country returns to its equilibrium position). In Senegal and to a lesser extent Burkina, shocks causing deviations from PPP are likely to last for a very long time; in the other countries convergence on PPP is somewhat faster. The persistence of PPP deviations entails substantial potential costs from adherence to a single currency. This might at first seem to be a puzzle, because previous studies have found little relative price variation in CFA countries. The resolution to this puzzle lies in the observation that the potential costs have not been actualized to a very large extent, because the external environment seldom throws up shocks generating large deviations from PPP. An example of this is the response of prices to interest rate shocks. The response profiles of the various CFA countries look very different, but none is large in absolute size, because interest rate changes do not have much impact on prices. This means that the absence of large internal price asymmetries in the past is no cause for complacency: if there were ever a shock causing a large deviation from PPP, it would persist for a long time and take a great deal of effort to neutralize. It is still vital that the monetary authorities keep track of price movements in individual countries. Quantifying the degree of asymmetry of past macroeconomic shocks is only part of the story, and no substitute for a fully structural macroeconomic model.

The structural model also identifies a large degree of persistence of shocks causing deviations from internal goods market equilibrium (i.e., deviations from the long-run IS curve); again the persistence is most marked in Senegal. This time, the persistence is an immediate problem for the monetary union, because there are often shocks causing substantial deviations from the long-run IS curve. A shock to the interest rate, for example, will lead to large and heterogeneous movements in output in the different UEMOA countries. Effective monetary policy in the future will require acknowledgement of this potential cost of monetary union membership, and policies to alleviate idiosyncratic recessions in individual UEMOA countries.

Finally, our estimates indicate that although there is long-run adjustment to Balance of Payments equilibrium for the monetary union as a whole, even with a fixed nominal exchange rate, full adjustment takes an inordinately long length of time. About $10 \%$ of Balance of Payments shock persists almost indefinitely. This means that the necessity of future devaluations of the CFA Franc cannot be ruled out entirely. 


\section{A Data Appendix}

Data is obtained at quarterly frequency from the IMF International Financial Statistics and individual Central Bank sources. Variable definitions are as follows:

$$
\begin{aligned}
R_{t}= & \text { annualised French government bond yield }[I F S], \\
S_{t}= & \text { CFA Franc - French Franc exchange rate }[\text { IFS }], \\
M_{t}= & \text { total money base, including M0 and demand deposits in domestic banks, across all } \\
& \text { the countries in CFA zone [Central Bank balance sheets], } \\
P_{i t}= & \text { consumer price index, in CFA Francs }[I F S], \\
Y_{t}^{*}= & \text { world trade, measured by total export volumes in billions of } \$ \mathrm{US}[I F S] .
\end{aligned}
$$

For these variables, the corresponding annual series are obtained through averaging. Data obtained at the annual frequency include:

$$
\begin{aligned}
Y_{i t}= & \text { real annual GDP in } 1990 \mathrm{CFA} \text { Francs [World Bank World Development Indicators], } \\
P_{i t}^{x}= & \text { export price index, weighted average of prices, in CFA Francs, of all commodities } \\
& \text { exported by country } i \\
P_{i t}^{z^{*}=} & \text { import price index, weighted average of prices, in CFA Francs, of all commodities } \\
& \text { imported by country } i .
\end{aligned}
$$

Corresponding quarterly series for outputs were obtained using quarterly electricity consumption figures from the BCEAO Notes d'Information et Statistiques, as described in the text. Quarterly import price and export price indices were derived using the interpolation procedures described in Lisman and Sandee (1964). The import price index measured in French Francs, is given by $P_{i t}^{z *}=P_{i t}^{z} / S_{t}$. 


\section{References}

Adam, C. (1992), "On the Dynamic Specification of Money Demand in Kenya", Journal of African Economies, 1, 233-70.

Easterly, W. and R. Levine (1997), "Africa's Growth Tragedy: Policies and Ethnic Divisions", Quarterly Journal of Economics, 112, 1203-50.

Fielding, D. and Bleaney, M. (2000) "Monetary Discipline and Inflation in Developing Countries: The Role of the Exchange Rate Regime", Oxford Economic Papers, $52,521-38$.

Fielding, D. and K. Shields (2001) "Modelling Macroeconomic Shocks in the CFA Franc Zone", Journal of Development Economics, 66, 199-223.

Fielding, D. and K. Shields (2005), "Economic Integration in West Africa: Does the CFA Make a Difference?", Economica (forthcoming).

Fielding, D., K. Lee and K. Shields (2004) "The Characteristics of Macroeconomic Shocks in the CFA Franc Zone", Journal of African Economies, 13, 488-517.

Garratt, A., K. Lee, M.H. Pesaran and Y. Shin (2003), "A Long Run Structural Macroeconometric Model of the UK", Economic Journal , 113, 412-455.

Hoffmaister, A. W., J. E. Roldós, and P. Wickham (1998) "Macroeconomic Fluctuations in Sub-Saharan Africa", IMF Staff Papers, 45, 132-60.

Koop, G., M.H. Pesaran and S.M. Potter (1996), "Impulse Response Analysis in Nonlinear Multivariate Models", Journal of Econometrics, 74, 119-147.

Lee, K.C. and M.H. Pesaran, (1993), "Persistence Profiles and Business Cycle Fluctuations in a Disaggregated Model of UK Output Growth", Ricerche Economiche, 47, 293-322.

Lisman, J.H.C. and J. Sandee, (1964), Derivation of Quarterly Figures from Annual Data, Applied Statistics, 13, 2, 87-90.

Pesaran, M.H., Y. Shin and R.J. Smith., (2001), "Bounds Testing Approaches to the Analysis of Level Relationships", Journal of Applied Econometrics, Special Issue in Honour of J.D. Sargan on the theme "Studies in Empirical Macroeconometrics", (eds) D.F. Hendry and M.H. Pesaran, 16, 289-326.

Stasavage, D. (1997) "The CFA Franc Zone and Fiscal Discipline", Journal of African Economies, 6, 132-67.

World Bank (2003) Millennium Development Goals, http://www.developmentgoals.org/Data.htm. 
Table 1a: ARDL Models for Long-Run LM and BP Relationships,

Equations (1) and (2), 1972-2000

\begin{tabular}{|c|c|c|c|}
\hline & $\Delta\left(m_{t}-p_{t}\right)$ & & $\Delta e_{t}$ \\
\hline intercept & $\begin{array}{c}-22.2773 \\
(8.154) \\
\end{array}$ & intercept & $\begin{array}{l}-15.9097 \\
(8.051)\end{array}$ \\
\hline trend & $\begin{array}{l}-.0205 \\
(.007)\end{array}$ & trend & $\begin{array}{l}-.0203 \\
(.008)\end{array}$ \\
\hline$m_{t-1}-p_{t-1}$ & $\begin{array}{l}-.3424 \\
(.102) \\
\end{array}$ & $e_{t-1}$ & $\begin{array}{l}-.5212 \\
(.170) \\
\end{array}$ \\
\hline$y_{t-1}$ & $\begin{array}{l}.8503 \\
(.304) \\
\end{array}$ & $y_{t-1}$ & $\begin{array}{l}.5952 \\
(.306) \\
\end{array}$ \\
\hline$R_{t-1}$ & $\begin{array}{l}-.4833 \\
(.647)\end{array}$ & $p_{t-1}-p_{t-1}^{x}$ & $\begin{array}{l}.0330 \\
(.133)\end{array}$ \\
\hline$\Delta p_{t-1}$ & $\begin{array}{l}-.3148 \\
(.376)\end{array}$ & $y_{t-1}^{*}$ & $\begin{array}{l}-.0067 \\
-.070)\end{array}$ \\
\hline$\Delta\left(m_{t-1}-p_{t-1}\right)$ & $\begin{array}{l}-.2210 \\
(.150)\end{array}$ & $s_{t}$ & $\begin{array}{l}.1970 \\
(.054) \\
\end{array}$ \\
\hline$\Delta y_{t}$ & $\begin{array}{l}.8258 \\
(.551)\end{array}$ & $\Delta e_{t-1}$ & $\begin{array}{l}.1903 \\
(.151) \\
\end{array}$ \\
\hline$\Delta y_{t-1}$ & $\begin{array}{l}-2.4168 \\
(.592)\end{array}$ & $\Delta y_{t}$ & \\
\hline$\Delta R_{t}$ & 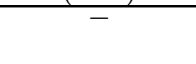 & $\Delta y_{t-1}$ & $\begin{array}{c}-1.0591 \\
(.464)\end{array}$ \\
\hline$\Delta R_{t-1}$ & $\begin{array}{l}-3.6330 \\
(.886)\end{array}$ & $\Delta\left(p_{t}-p_{t}^{x}\right)$ & $\begin{array}{l}.3304 \\
(.136) \\
\end{array}$ \\
\hline$\Delta \Delta p_{t}$ & $\begin{array}{l}-.9292 \\
(.199) \\
\end{array}$ & $\Delta\left(p_{t-1}-p_{t-1}^{x}\right)$ & \\
\hline \multirow[t]{2}{*}{$\Delta \Delta p_{t-1}$} & $\begin{array}{l}-.2976 \\
(.233) \\
\end{array}$ & $\Delta y_{t}^{*}$ & $\begin{array}{l}-.1796 \\
(.149) \\
\end{array}$ \\
\hline & & $\Delta y_{t-1}^{*}$ & $\begin{array}{l}.2780 \\
(.121) \\
\end{array}$ \\
\hline$\overline{\bar{R}}^{2}$ & .665 & $\overline{\bar{R}}^{2}$ & .736 \\
\hline$\hat{\sigma}$ & .049 & $\hat{\sigma}$ & .042 \\
\hline 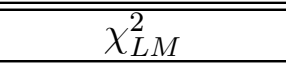 & ב.095\{0.67\} & 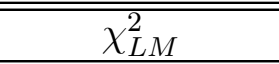 & $1,10\{0.42\}$ \\
\hline$F_{S C}$ & $0.62\{0.56\}$ & $F_{S C}$ & $3.61\{0.94\}$ \\
\hline$F_{F F}$ & $3.82\{0.93\}$ & $F_{F F}$ & $0.06\{0.19\}$ \\
\hline$F_{H}$ & $0.25\{0.38\}$ & $F_{H}$ & $0.01\{0.07\}$ \\
\hline$\chi_{N}^{2}$ & $0.41\{0.19\}$ & $\chi_{N}^{2}$ & $1.88\{0.06\}$ \\
\hline
\end{tabular}

Notes: The associated error correction terms are given by

$$
\begin{aligned}
\widehat{\xi}_{L M, t} & =m_{t}-p_{t}-2.483 y_{t}+1.412 R_{t}+3.678 \Delta p_{t}-0.060 t \\
\widehat{\xi}_{B P, t} & =e_{t}-1.142 y_{t}-0.063\left(p_{t}-p_{t}^{x}\right)+0.013 y_{t}^{*}-0.378 s_{t}+0.039 t
\end{aligned}
$$

Standard errors are given in (.), p-values in \{.\}. $\bar{R}^{2}$ is the adjusted squared multiple correlation coefficient, $\widehat{\sigma}$ is the standard error of the regression and $\chi_{L M}^{2}$ is a chi-squared test statistic for the joint exclusion restriction of regressors from the regression equation as according to the specification search rule described in the text (excluded regressors indicated by ' - ' in the Table). The diagnostics are F-statistics for serial correlation (SC), functional form (FF) and heteroscedasticity $(\mathrm{H})$, and a chi-squared test for normality $(\mathrm{N})$. 
Table 1b: ARDL Models for Long-Run PPP Relationships, Equation (3), 1972-2000

\begin{tabular}{|c|c|c|c|c|}
\hline & $\Delta p_{1 t}(\mathrm{BFA})$ & $\Delta p_{2 t}(\mathrm{MLI})$ & $\Delta p_{3 t}(\mathrm{SEN})$ & $\Delta p_{4 t}(\mathrm{TGO})$ \\
\hline intercept & $\begin{array}{l}.3058 \\
(.093) \\
\end{array}$ & $\begin{array}{l}.0218 \\
(.072)\end{array}$ & $\begin{array}{l}-.2941 \\
(.118)\end{array}$ & $\begin{array}{l}3083 \\
(.142) \\
\end{array}$ \\
\hline$p_{i, t-1}$ & $\begin{array}{l}-.4601 \\
(.154)\end{array}$ & $\begin{array}{l}-.5365 \\
(.155)\end{array}$ & $\begin{array}{l}-.1787 \\
(.065)\end{array}$ & $\begin{array}{l}-.5638 \\
(.174)\end{array}$ \\
\hline$p_{t-1}$ & $\begin{array}{l}.3900 \\
(.136)\end{array}$ & $\begin{array}{l}.5414 \\
(.161)\end{array}$ & $\begin{array}{l}.2439 \\
(.073)\end{array}$ & $\begin{array}{l}.4896 \\
(.152)\end{array}$ \\
\hline$s_{t}$ & $\begin{array}{l}-.0695 \\
(.030)\end{array}$ & $\begin{array}{l}.0487 \\
(.027) \\
\end{array}$ & $\begin{array}{l}-.0693 \\
(.022)\end{array}$ & $\begin{array}{l}.0744 \\
(.040) \\
\end{array}$ \\
\hline \multicolumn{5}{|l|}{$\Delta p_{i, t-1}$} \\
\hline$\Delta p_{t}$ & $\begin{array}{l}.6589 \\
(.108) \\
\end{array}$ & $\begin{array}{l}.6230 \\
(.114) \\
\end{array}$ & $\begin{array}{l}.8655 \\
(.107) \\
\end{array}$ & $\begin{array}{l}.8944 \\
(.169) \\
\end{array}$ \\
\hline \multicolumn{5}{|l|}{$\Delta p_{t-1}$} \\
\hline $\bar{R}^{2}$ & .603 & .595 & .799 & .640 \\
\hline$\hat{\sigma}$ & .035 & .040 & .025 & .058 \\
\hline$\chi_{L M}^{2}$ & $6.05\{0.95\}$ & $1.94\{0.62\}$ & $0.95\{0.38\}$ & $2.43\{0.70\}$ \\
\hline$\chi_{L M+}^{2}$ & $7.89\{0.98\}$ & $2.04\{0.44\}$ & $6.71\{0.92\}$ & $7.03\{0.93\}$ \\
\hline$F_{S C}$ & $2.44\{0.88\}$ & $4.94\{0.96\}$ & $0.03\{0.13\}$ & $1.09\{0.69\}$ \\
\hline$\overline{F_{F F}}$ & $4.14\{0.96\}$ & $1.87\{0.82\}$ & $4.14\{0.94\}$ & $0.27\{0.39\}$ \\
\hline$F_{H}$ & $0.09\{0.24\}$ & $6.88\{0.99\}$ & $21.28\{1.00\}$ & $1.35\{0.75\}$ \\
\hline$\chi_{N}^{2}$ & $0.07\{0.03\}$ & $0.13\{0.06\}$ & $0.40\{0.18\}$ & $0.98\{0.39\}$ \\
\hline
\end{tabular}

Notes: See notes to Table 1a. $\chi_{L M+}^{2}$ is a chi-squared test statistic for the exclusion restrictions tested by $\chi_{L M}^{2}$ plus the restriction that the coefficient on $p_{i, t-1}$ and $p_{t-1}$ are of equal and opposite sign. Under the latter assumption, the associated error correction terms are given by

$$
\widehat{\xi}_{P P P i, t}=p_{i t}-p_{t}+c_{i 1} s_{t}
$$


Table 1c: ARDL Models for Long-Run IS Relationships, Equation (4), 1972-2000

\begin{tabular}{|c|c|c|c|c|c|}
\hline & $\Delta y_{1 t}(\mathrm{BFA})$ & $\Delta y_{2 t}(\mathrm{MLI})$ & $\Delta y_{3 t}(\mathrm{SEN})$ & $\Delta y_{4 t}(\mathrm{TGO})$ & $\Delta y_{5 t}(\mathrm{CIV})$ \\
\hline intercept & $\begin{array}{l}21.8143 \\
(5.428)\end{array}$ & $\begin{array}{l}14.9790 \\
(4.174)\end{array}$ & $\begin{array}{l}21.0143 \\
(7.559)\end{array}$ & $\begin{array}{l}7.9638 \\
(3.151)\end{array}$ & $\begin{array}{l}11.2460 \\
(2.690)\end{array}$ \\
\hline trend & $\begin{array}{l}.0331 \\
(.009) \\
\end{array}$ & $\begin{array}{l}.0178 \\
(.005) \\
\end{array}$ & $\begin{array}{l}.0245 \\
(.009) \\
\end{array}$ & & $\begin{array}{l}-.0008 \\
(.003) \\
\end{array}$ \\
\hline$y_{i, t-1}$ & $\begin{array}{l}-.8136 \\
(.189)\end{array}$ & $\begin{array}{l}-.5614 \\
(.161)\end{array}$ & $\begin{array}{l}-.8295 \\
(.271)\end{array}$ & $\begin{array}{l}-.7439 \\
(.129)\end{array}$ & $\begin{array}{l}-.4157 \\
(.103)\end{array}$ \\
\hline$R_{t-1}-\Delta p_{i, t-1}$ & $\begin{array}{l}\frac{1.1000}{(.1500} \\
(.111)\end{array}$ & $\begin{array}{l}-.0134 \\
(.3456)\end{array}$ & $\begin{array}{l}(.41) \\
(.2600 \\
(.133)\end{array}$ & $\begin{array}{l}(.12769 \\
(.074)\end{array}$ & $\begin{array}{l}(.1007 \\
. .109)\end{array}$ \\
\hline$e_{i, t-1}$ & $\begin{array}{l}.10776 \\
.0751) \\
(.051)\end{array}$ & $\begin{array}{l}. .2230 \\
. .067)\end{array}$ & $\begin{array}{l}.10026 \\
.0826) \\
(.049)\end{array}$ & $\begin{array}{l}(.0321 \\
(.057)\end{array}$ & $\begin{array}{l}.1072 \\
.1072 \\
(.073)\end{array}$ \\
\hline$y_{t-1}^{*}$ & $\begin{array}{l}-.0216 \\
-.0286 \\
\end{array}$ & $\begin{array}{l}-.0083 \\
(.141) \\
\end{array}$ & $\begin{array}{l}-.0275 \\
(.047)\end{array}$ & $\begin{array}{l}.1819 \\
. .031) \\
\end{array}$ & $\begin{array}{l}.0971 \\
. .051) \\
\end{array}$ \\
\hline$\overline{\mathrm{D} 93_{t}}$ & & & & $\begin{array}{l}-.2043 \\
(.039)\end{array}$ & \\
\hline$\Delta y_{i, t-1}$ & - & $\begin{array}{l}.2573 \\
(.185) \\
\end{array}$ & $\begin{array}{l}.2557 \\
(.226) \\
\end{array}$ & & $\begin{array}{l}.4305 \\
(.168) \\
\end{array}$ \\
\hline$\Delta\left(R_{t}-\Delta p_{i, t}\right)$ & $\begin{array}{l}-.0767 \\
(.063) \\
\end{array}$ & & & - & \\
\hline$\Delta\left(R_{t-1}-\Delta p_{i, t-1}\right)$ & $\begin{array}{l}.0357 \\
.051)\end{array}$ & $\begin{array}{l}.1646 \\
. .091)\end{array}$ & $\begin{array}{l}.1367 \\
(.088)\end{array}$ & - & $\begin{array}{l}.1222 \\
(.070)\end{array}$ \\
\hline$\Delta e_{t}$ & $\begin{array}{l}.0603 \\
(.060) \\
\end{array}$ & & & $\begin{array}{l}-.0403 \\
(.051)\end{array}$ & \\
\hline$\Delta e_{t-1}$ & $\begin{array}{l}-.0731 \\
(.070)\end{array}$ & - & - & & $\begin{array}{l}-.1514 \\
(.091)\end{array}$ \\
\hline$\Delta y_{t}^{*}$ & & - & - & $\begin{array}{l}.2800 \\
. .089) \\
\end{array}$ & \\
\hline \multicolumn{6}{|l|}{$\Delta y_{t-1}^{*}$} \\
\hline$\overline{\bar{R}}^{2}$ & .296 & .279 & .264 & .705 & .509 \\
\hline$\hat{\sigma}$ & .028 & .042 & .039 & .035 & .034 \\
\hline$\chi_{L M}^{2}$ & $3.82\{0.72\}$ & $1.90\{0.14\}$ & $1.62\{0.10\}$ & $4.56\{0.53\}$ & $0.92\{0.08\}$ \\
\hline$F_{S C}$ & $1.52\{0.77\}$ & $0.48\{0.50\}$ & $0.00\{0.04\}$ & $1.46\{0.76\}$ & $0.59\{0.55\}$ \\
\hline$F_{F F}$ & $0.59\{0.55\}$ & $0.27\{0.39\}$ & $0.01\{0.07\}$ & $1.48\{0.76\}$ & $3.22\{0.91\}$ \\
\hline$F_{H}$ & $0.43\{0.47\}$ & $0.51\{0.52\}$ & $0.16\{0.30\}$ & $0.31\{0.42\}$ & $0.06\{0.19\}$ \\
\hline$\chi_{N}^{2}$ & $0.81\{0.33\}$ & $3.89\{0.86\}$ & $0.55\{0.24\}$ & $0.66\{0.28\}$ & $0.02\{0.01\}$ \\
\hline
\end{tabular}

Notes: See notes to Table 1a. The associated error correction terms are given by

$$
\begin{aligned}
& \widehat{\xi}_{I S 1, t}=y_{t}-0.096 e_{1 t}+0.184\left(R_{t}-\Delta p_{1 t}\right)+0.035 y_{t}^{*}-0.041 t, \quad(\mathrm{BFA}) \\
& \widehat{\xi}_{I S 2, t}=y_{t}-0.397 e_{2 t}+0.612\left(R_{t}-\Delta p_{2 t}\right)+0.015 y_{t}^{*}-0.032 t, \quad(\mathrm{MLI}) \\
& \widehat{\xi}_{I S 3, t}=y_{t}-0.100 e_{3 t}+0.313\left(R_{t}-\Delta p_{3 t}\right)+0.033 y_{t}^{*}-0.030 t, \quad(\mathrm{SEN}) \\
& \widehat{\xi}_{I S 4, t}=y_{t}+0.043 e_{4 t}+0.238\left(R_{t}-\Delta p_{4 t}\right)-0.244 y_{t}^{*}+0.275 D 93_{t}, \quad \text { (TGO) } \\
& \widehat{\xi}_{I S 5, t}=y_{t}-0.258 e_{5 t}+0.424\left(R_{t}-\Delta p_{5 t}\right)-0.234 y_{t}^{*}-0.002 t, \quad(\mathrm{CIV})
\end{aligned}
$$


Table 2a: Equilibrium Correction Model for Money Growth, 1988q4 - 2000q4

\begin{tabular}{|c|c|}
\hline & $\Delta m_{t}$ \\
\hline intercept & $\begin{array}{l}-0.2328 \\
(0.2211)\end{array}$ \\
\hline$\widehat{\xi}_{L M, t-1}$ & $\begin{array}{l}-0.0134 \\
(0.0207)\end{array}$ \\
\hline$\widehat{\xi}_{B P, t-1}$ & - \\
\hline$\Delta m_{t-1}$ & $\begin{array}{l}-0.3271 \\
(0.1423)\end{array}$ \\
\hline$\Delta m_{t-4}$ & \\
\hline$\Delta y_{t-1}$ & $\begin{array}{l}-0.0863 \\
(0.0887)\end{array}$ \\
\hline$\Delta y_{t-4}$ & \\
\hline$\Delta p_{t-1}$ & $\begin{array}{l}0.3701 \\
(0.2659)\end{array}$ \\
\hline$\Delta p_{t-4}$ & \\
\hline$\Delta R_{t}$ & $\begin{array}{c}1.6745 \\
(1.9502)\end{array}$ \\
\hline$\Delta R_{t-1}$ & $\begin{array}{l}-1.4452 \\
(1.6122)\end{array}$ \\
\hline$\Delta R_{t-4}$ & \\
\hline$\Delta e_{t}$ & $\begin{array}{l}-0.5890 \\
(0.5433)\end{array}$ \\
\hline$\Delta e_{t-1}$ & $\begin{array}{l}0.1844 \\
(0.1657) \\
\end{array}$ \\
\hline$\Delta e_{t-4}$ & - \\
\hline$\Delta\left(p_{t}-p_{t}^{x}\right)$ & $\begin{array}{l}-0.8100 \\
(0.4736) \\
\end{array}$ \\
\hline$\Delta\left(p_{t-1}-p_{t-1}^{x}\right)$ & - \\
\hline$\Delta\left(p_{t-4}-p_{t-4}^{x}\right)$ & - \\
\hline$\Delta y_{t}^{*}$ & $\begin{array}{l}-0.2790 \\
(0.2539)\end{array}$ \\
\hline$\Delta y_{t-1}^{*}$ & \\
\hline$\Delta y_{t-4}^{*}$ & $\begin{array}{l}-0.2172 \\
(0.2153)\end{array}$ \\
\hline 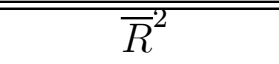 & 0.869 \\
\hline$\hat{\sigma}$ & 0.035 \\
\hline$\overline{\chi_{L M}^{2}}$ & $1313.11\{0.71\}$ \\
\hline$F_{S C}$ & $2.78\{0.95\}$ \\
\hline$F_{F F}$ & $5.49\{0.97\}$ \\
\hline$F_{H}$ & $0.00\{0.04\}$ \\
\hline$\chi_{N}^{2}$ & $0.68\{0.29\}$ \\
\hline
\end{tabular}

Notes: Standard errors are given in (.), p-values in $\{.\} . \bar{R}^{2}$ is the adjusted squared multiple correlation coefficient, $\widehat{\sigma}$ is the standard error of the regression and $\chi_{L M}^{2}$ is a chi-squared test statistic for the joint exclusion restriction of regressors from the regression equation as according to the specification search rule described in the text (excluded regressors indicated by ' -' in the Table). The diagnostics are F-statistics for serial correlation (SC), functional form (FF) and heteroscedasticity $(\mathrm{H})$, and a chi-squared test for normality $(\mathrm{N})$. 
Table 2b: Equilibrium Correction Model for Price Inflation, 1988q4 - 2000q4

\begin{tabular}{|c|c|c|c|c|c|}
\hline & $\Delta p_{1 t}(\mathrm{BFA})$ & $\Delta p_{2 t}(\mathrm{MLI})$ & $\Delta p_{3 t}(\mathrm{SEN})$ & $\Delta p_{4 t}(\mathrm{TGO})$ & $\Delta p_{5 t}(\mathrm{CIV})$ \\
\hline intercept & $\begin{array}{l}0.0630 \\
(0.0786)\end{array}$ & $\begin{array}{l}-0.2884 \\
(0.1388)\end{array}$ & $\begin{array}{c}0.0291 \\
(0.0066)\end{array}$ & $\begin{array}{l}-0.0025 \\
(0.0076)\end{array}$ & $\begin{array}{l}0.2861 \\
(0.0909)\end{array}$ \\
\hline$\widehat{\xi}_{L M, t-1}$ & $\begin{array}{c}0.0421 \\
(0.0310)\end{array}$ & - & - & - & $\begin{array}{c}0.0255 \\
(0.0084)\end{array}$ \\
\hline$\widehat{\xi}_{B P, t-1}$ & $\begin{array}{l}-0.0216 \\
(0.0455)\end{array}$ & - & - & - & - \\
\hline$\widehat{\xi}_{I S, i t-1}$ & $\begin{array}{c}0.0557 \\
(0.0184) \\
\end{array}$ & $\begin{array}{l}0.0605 \\
(0.0275)\end{array}$ & - & - & - \\
\hline$\widehat{\xi_{P P P, 1 t-1}}$ & $\begin{array}{l}-0.5572 \\
(0.1521)\end{array}$ & $\begin{array}{c}0.1089 \\
(0.2103) \\
\end{array}$ & - & $\begin{array}{c}0.4970 \\
(0.1988)\end{array}$ & $\begin{array}{l}0.5227 \\
(0.1707)\end{array}$ \\
\hline$\widehat{\xi}_{P P P, 2 t-1}$ & - & - & $\begin{array}{l}-0.1387 \\
(0.1669)\end{array}$ & $\begin{array}{c}0.6827 \\
(0.2086)\end{array}$ & - \\
\hline$\widehat{\hat{\xi}_{P P P, 3 t-1}}$ & - & $\begin{array}{l}-0.4264 \\
(0.1249)\end{array}$ & $\begin{array}{l}-0.1315 \\
(0.1682) \\
\end{array}$ & $\begin{array}{l}0.5305 \\
(0.1870) \\
\end{array}$ & - \\
\hline$\widehat{\xi}_{P P P, 4 t-1}$ & - & $\begin{array}{c}0.1391 \\
(0.1706)\end{array}$ & - & $\begin{array}{c}0.6875 \\
(0.1551)\end{array}$ & $\begin{array}{l}0.5156 \\
(0.1407)\end{array}$ \\
\hline$\Delta p_{i t-1}$ & - & $\begin{array}{l}0.2606 \\
(0.1269)\end{array}$ & & $\begin{array}{l}0.2412 \\
(0.1037)\end{array}$ & $\begin{array}{l}0.2225 \\
(0.1554)\end{array}$ \\
\hline$\Delta p_{-i, t-1}$ & $\begin{array}{l}0.3256 \\
(0.1806)\end{array}$ & & & & $\begin{array}{l}-0.3319 \\
(0.1601)\end{array}$ \\
\hline$\Delta y_{t-1}$ & & $\begin{array}{l}-0.0437 \\
(0.0430)\end{array}$ & $\begin{array}{l}-0.0321 \\
(0.0361)\end{array}$ & $\begin{array}{l}-0.0412 \\
(0.0362)\end{array}$ & $\begin{array}{c}0.0824 \\
(0.0331)\end{array}$ \\
\hline$\Delta m_{t-1}$ & - & & $\begin{array}{l}0.0782 \\
(0.0627)\end{array}$ & - & \\
\hline$\Delta R_{t}$ & - & - & $\begin{array}{l}0.5478 \\
(0.6402)\end{array}$ & - & - \\
\hline$\Delta R_{t-1}$ & - & $\begin{array}{l}-1.3415 \\
(0.7884)\end{array}$ & & $\begin{array}{l}1.7543 \\
(0.8023)\end{array}$ & $\begin{array}{l}-1.0221 \\
(0.5616)\end{array}$ \\
\hline$\Delta e_{t}$ & $\begin{array}{l}-0.4106 \\
(0.1811)\end{array}$ & & - & & $\begin{array}{l}-0.4786 \\
(0.1955)\end{array}$ \\
\hline$\Delta e_{t-1}$ & $\begin{array}{l}0.1049 \\
(0.0804)\end{array}$ & - & - & - & $\begin{array}{l}0.2812 \\
(0.0619) \\
\end{array}$ \\
\hline$\Delta\left(p_{t}-p_{t}^{x}\right)$ & $\begin{array}{l}-0.3563 \\
(0.1528)\end{array}$ & $=$ & $\begin{array}{l}-0.0397 \\
(0.0495)\end{array}$ & $=$ & $\begin{array}{l}-0.3334 \\
(0.1687)\end{array}$ \\
\hline$\Delta\left(p_{t-1}-p_{t-1}^{x}\right)$ & - & - & - & - & - \\
\hline$\Delta y_{t}^{*}$ & $\begin{array}{l}-0.0319 \\
(0.0644)\end{array}$ & - & - & $\begin{array}{l}-0.1422 \\
(0.0923)\end{array}$ & $\begin{array}{l}0.1064 \\
(0.0772)\end{array}$ \\
\hline$\Delta y_{t-1}^{*}$ & $\begin{array}{l}-0.0743 \\
(0.0630) \\
\end{array}$ & $\begin{array}{c}0.1137 \\
(0.1040) \\
\end{array}$ & - & $\begin{array}{l}-0.0923 \\
(0.0960) \\
\end{array}$ & \\
\hline$\overline{\bar{R}}^{2}$ & 0.839 & 0.786 & 0.774 & 0.847 & 0.793 \\
\hline$\hat{\sigma}$ & 0.012 & 0.016 & 0.016 & 0.014 & 0.012 \\
\hline 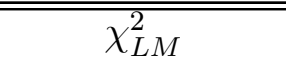 & $16.97\{0.92\}$ & $8.63\{0.27\}$ & $3033.31\{1.00\}$ & 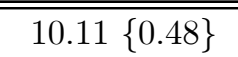 & $21.57\{0.98\}$ \\
\hline$F_{S C}$ & $0.37\{0.17\}$ & $0.67\{0.39\}$ & $2.07\{0.89\}$ & $0.71\{0.41\}$ & $0.32\{0.14\}$ \\
\hline$F_{F F}$ & $0.01\{0.08\}$ & $0.29\{0.41\}$ & $3.78\{0.94\}$ & $0.20\{0.35\}$ & $16.96\{1.00\}$ \\
\hline$F_{H}$ & $0.72\{0.60\}$ & $0.53\{0.53\}$ & $0.17\{0.32\}$ & $0.78\{0.62\}$ & $1.25\{0.73\}$ \\
\hline$\chi_{N}^{2}$ & $0.45\{0.20\}$ & $1.87\{0.61\}$ & $0.31\{0.15\}$ & $0.89\{0.36\}$ & $1.05\{0.41\}$ \\
\hline
\end{tabular}

Notes: See notes to Table 2a. 
Table 2c: Equilibrium Correction Model for Output Growth, 1988q4 - 2000q4

\begin{tabular}{|c|c|c|c|c|c|}
\hline & $\Delta y_{1 t}(\mathrm{BFA})$ & $\Delta y_{2 t}(\mathrm{MLI})$ & $\Delta y_{3 t}(\mathrm{SEN})$ & $\Delta y_{4 t}(\mathrm{TGO})$ & $\Delta y_{5 t}(\mathrm{CIV})$ \\
\hline intercept & $\begin{array}{l}-0.4543 \\
(0.5271)\end{array}$ & $\begin{array}{l}0.3443 \\
(0.4009)\end{array}$ & $\begin{array}{l}2.5407 \\
(0.7622)\end{array}$ & $\begin{array}{l}-0.0739 \\
(0.2150)\end{array}$ & $\begin{array}{l}6.8447 \\
(1.0987)\end{array}$ \\
\hline$\widehat{\xi}_{L M, t-1}$ & - & $\begin{array}{l}-0.1117 \\
(0.0845)\end{array}$ & - & - & $\begin{array}{l}-0.2095 \\
(0.1670)\end{array}$ \\
\hline$\widehat{\xi}_{B P, t-1}$ & $\begin{array}{l}-1.7725 \\
(0.2269) \\
\end{array}$ & - & $\begin{array}{l}-0.3215 \\
(0.1578) \\
\end{array}$ & - & $\begin{array}{c}0.4179 \\
(0.2571) \\
\end{array}$ \\
\hline$\widehat{\xi_{I S, i t-1}}$ & $\begin{array}{l}-1.9255 \\
(0.2190) \\
\end{array}$ & $\begin{array}{l}-0.3411 \\
(0.1891)\end{array}$ & $\begin{array}{l}-0.7419 \\
(0.2154)\end{array}$ & $\begin{array}{l}-0.0158 \\
(0.0426)\end{array}$ & $\begin{array}{l}-1.2630 \\
(0.1867) \\
\end{array}$ \\
\hline$\widehat{\xi}_{P P P, 1 t-1}$ & $\begin{array}{l}-1.1476 \\
(1.5412) \\
\end{array}$ & - & $\begin{array}{l}-1.6238 \\
(0.8067) \\
\end{array}$ & - & $\begin{array}{l}1.0829 \\
(1.2277) \\
\end{array}$ \\
\hline$\widehat{\xi}_{P P P, 2 t-1}$ & - & - & $\begin{array}{l}-1.9277 \\
(0.7295) \\
\end{array}$ & - & - \\
\hline$\widehat{\xi}_{P P P, 3 t-1}$ & - & - & - & - & - \\
\hline$\widehat{\xi}_{P P P, 4 t-1}$ & - & - & $\begin{array}{l}-0.4393 \\
(0.6398)\end{array}$ & - & - \\
\hline$\Delta y_{i t-1}$ & $\begin{array}{c}0.5183 \\
(0.1136) \\
\end{array}$ & $\begin{array}{l}-0.1283 \\
(0.1807) \\
\end{array}$ & $\begin{array}{l}-0.1326 \\
(0.1277) \\
\end{array}$ & $\begin{array}{l}-0.1971 \\
(0.1683)\end{array}$ & $=$ \\
\hline$\Delta y_{-i, t-1}$ & & - & & & - \\
\hline$\Delta p_{t-1}$ & $\begin{array}{l}-1.8873 \\
(0.9326) \\
\end{array}$ & - & - & - & - \\
\hline$\Delta m_{t-1}$ & - & - & $\begin{array}{l}0.4031 \\
(0.2864) \\
\end{array}$ & $\overline{-}$ & $\begin{array}{l}0.1664 \\
(0.4204)\end{array}$ \\
\hline$\Delta R_{t}$ & - & - & & & \\
\hline$\Delta R_{t-1}$ & - & - & - & $\begin{array}{l}-3.6064 \\
(3.7347) \\
\end{array}$ & - \\
\hline$\Delta e_{t}$ & $\begin{array}{l}-1.5821 \\
(0.4736) \\
\end{array}$ & $\begin{array}{l}0.5157 \\
(0.3950) \\
\end{array}$ & $\begin{array}{l}1.1011 \\
(1.2328) \\
\end{array}$ & & $\begin{array}{c}1.5341 \\
(0.5502) \\
\end{array}$ \\
\hline$\Delta e_{t-1}$ & $\begin{array}{l}2.3263 \\
(0.5589)\end{array}$ & & $\begin{array}{l}0.5047 \\
(0.4723)\end{array}$ & & \\
\hline$\Delta\left(p_{t}-p_{t}^{x}\right)$ & & $\begin{array}{l}1.3494 \\
(1.3878) \\
\end{array}$ & $\begin{array}{l}2.1377 \\
(1.0251)\end{array}$ & $\begin{array}{l}-0.5712 \\
(0.3190)\end{array}$ & \\
\hline$\Delta\left(p_{t-1}-p_{t-1}^{x}\right)$ & - & $\begin{array}{l}-1.8132 \\
(1.3072)\end{array}$ & - & $\begin{array}{c}0.6894 \\
(0.3866)\end{array}$ & $\begin{array}{c}1.8566 \\
(1.3571)\end{array}$ \\
\hline$\Delta y_{t}^{*}$ & - & & - & & \\
\hline$\Delta y_{t-1}^{*}$ & $\begin{array}{l}-0.8919 \\
(0.6309)\end{array}$ & $\begin{array}{c}0.3634 \\
(0.3712)\end{array}$ & - & $\begin{array}{l}0.7072 \\
(0.4788)\end{array}$ & $\begin{array}{l}-0.9822 \\
(0.5329)\end{array}$ \\
\hline$\overline{\bar{R}}^{2}$ & 0.880 & 0.788 & 0.682 & 0.524 & 0.672 \\
\hline$\hat{\sigma}$ & 0.116 & 0.073 & 0.067 & 0.073 & 0.100 \\
\hline 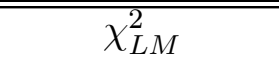 & $24.71\{0.97\}$ & $12.94\{0.55\}$ & $13.72\{0.87\}$ & 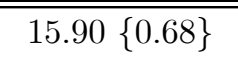 & $14.10\{0.71\}$ \\
\hline$F_{S C}$ & $0.42\{0.21\}$ & $3.55\{0.98\}$ & $1.01\{0.58\}$ & $2.56\{0.94\}$ & $2.03\{0.89\}$ \\
\hline$\overline{F F F}$ & $0.13\{0.28\}$ & $0.04\{0.17\}$ & $0.01\{0.09\}$ & $1.85\{0.82\}$ & $0.09\{0.24\}$ \\
\hline$F_{H}$ & $0.09\{0.23\}$ & $1.05\{0.69\}$ & $0.04\{0.15\}$ & $0.03\{0.14\}$ & $3.09\{0.71\}$ \\
\hline$\chi_{N}^{2}$ & $0.78\{0.32\}$ & $4.60\{0.90\}$ & $4.54\{0.90\}$ & $3.35\{0.81\}$ & $33.71\{1.00\}$ \\
\hline
\end{tabular}

Notes: See notes to Table 2a. 
Table 2d: Exogenous Variable Equations, 1988q4 - 2000q4

\begin{tabular}{|c|c|c|c|c|c|c|c|c|}
\hline & $\Delta R_{t}$ & $\Delta p_{1 t}^{z}(\mathrm{BFA})$ & $\Delta p_{2 t}^{z}(\mathrm{MLI})$ & $\Delta p_{3 t}^{z}(\mathrm{SEN})$ & $\Delta p_{4 t}^{z}(\mathrm{TGO})$ & $\Delta p_{5 t}^{z}(\mathrm{CIV})$ & $\Delta p_{t}^{x}$ & $\Delta y_{t}^{*}$ \\
\hline intercept & $\begin{array}{l}-0.0006 \\
(0.0005)\end{array}$ & $\begin{array}{c}-0.0033 \\
(0.0092)\end{array}$ & $\begin{array}{l}-0.0005 \\
(0.0045)\end{array}$ & $\begin{array}{l}-0.0015 \\
(0.0057)\end{array}$ & $\begin{array}{l}-0.0001 \\
(0.0089)\end{array}$ & $\begin{array}{l}-0.0019 \\
(0.0044)\end{array}$ & $\begin{array}{l}-0.0048 \\
(0.0047)\end{array}$ & $\begin{array}{l}-0.0147 \\
(0.0108)\end{array}$ \\
\hline$\Delta R_{t-1}$ & $\begin{array}{c}0.3673 \\
(0.1308)\end{array}$ & $*$ & $*$ & $*$ & $*$ & $*$ & $*$ & $*$ \\
\hline$\Delta R_{t-4}$ & $\begin{array}{l}-0.3295 \\
(0.1233)\end{array}$ & $*$ & $*$ & $*$ & $*$ & * & $*$ & $*$ \\
\hline$\Delta p_{1 t-1}^{z}$ & $*$ & $\begin{array}{l}0.5080 \\
(0.0785)\end{array}$ & $*$ & $*$ & $*$ & $*$ & $*$ & $*$ \\
\hline$\Delta p_{1 t-4}^{z}$ & * & $\begin{array}{l}-0.1831 \\
(0.0636)\end{array}$ & $*$ & $*$ & $*$ & $*$ & $*$ & $*$ \\
\hline$\Delta p_{2 t-1}^{z}$ & $*$ & $*$ & $\begin{array}{c}0.4914 \\
(0.0416) \\
\end{array}$ & $*$ & $*$ & $*$ & $*$ & $*$ \\
\hline$\Delta p_{2 t-4}^{z}$ & * & * & $\begin{array}{l}-0.1619 \\
(0.0306)\end{array}$ & $*$ & $*$ & $*$ & $*$ & $*$ \\
\hline$\Delta p_{3 t-1}^{z}$ & $*$ & $*$ & $*$ & $\begin{array}{c}0.5267 \\
(0.0511)\end{array}$ & $*$ & $*$ & $*$ & $*$ \\
\hline$\Delta p_{3 t-4}^{z}$ & $*$ & * & * & $\begin{array}{l}-0.1467 \\
(0.0382)\end{array}$ & * & $*$ & $*$ & $*$ \\
\hline$\Delta p_{4 t-1}^{z}$ & $*$ & * & * & $*$ & $\begin{array}{c}0.4838 \\
(0.0754) \\
\end{array}$ & * & $*$ & $*$ \\
\hline$\Delta p_{4 t-4}^{z}$ & * & * & * & $*$ & $\begin{array}{l}-0.1781 \\
(0.0594) \\
\end{array}$ & $*$ & $*$ & * \\
\hline$\Delta p_{5 t-1}^{z}$ & * & * & * & * & * & $\begin{array}{c}0.5606 \\
(0.0489) \\
\end{array}$ & * & $*$ \\
\hline$\Delta p_{5 t-4}^{z}$ & * & * & * & * & $*$ & $\begin{array}{l}-0.1249 \\
(0.0370)\end{array}$ & $*$ & * \\
\hline$\Delta p_{t-1}^{x}$ & * & * & * & $*$ & * & $*$ & $\begin{array}{l}-0.5199 \\
(0.0447)\end{array}$ & $*$ \\
\hline$\Delta p_{t-4}^{x}$ & * & * & $*$ & $*$ & $*$ & $*$ & $\begin{array}{l}-0.1223 \\
(0.0322)\end{array}$ & $*$ \\
\hline$\Delta y_{t-1}^{*}$ & * & * & * & * & * & * & * & $\begin{array}{c}0.0960 \\
(0.1525) \\
\end{array}$ \\
\hline$\Delta y_{t-4}^{*}$ & * & $*$ & * & * & * & $*$ & * & - \\
\hline $\bar{R}^{2}$ & 0.238 & 0.840 & 0.960 & 0.937 & 0.861 & 0.945 & 0.959 & 0.770 \\
\hline$\widehat{\sigma}$ & 0.004 & 0.026 & 0.013 & 0.016 & 0.024 & 0.012 & 0.013 & 0.030 \\
\hline$\overline{\chi_{L M}^{2}}$ & - & - & - & - & - & - & - & $1.74\{0.06\}$ \\
\hline$F_{S C}$ & $0.91\{0.53\}$ & $2.23\{0.91\}$ & $2.77\{0.96\}$ & $5.21\{1.00\}$ & $1.73\{0.83\}$ & $10.84\{1.00\}$ & $6.12\{1.00\}$ & $0.80\{0.47\}$ \\
\hline$F_{F F}$ & $0.00\{0.00\}$ & $0.59\{0.55\}$ & $20.45\{1.00\}$ & $3.27\{0.92\}$ & $1.93\{0.83\}$ & $0.09\{0.23\}$ & $1.15\{0.71\}$ & $0.29\{0.41\}$ \\
\hline$F_{H}$ & $0.00\{0.00\}$ & $0.34\{0.33\}$ & $0.11\{0.26\}$ & $1.17[0.71]$ & $0.12\{0.27\}$ & $1.21\{0.72\}$ & $1.28\{0.74\}$ & $0.02\{0.10\}$ \\
\hline$\chi_{N}^{2}$ & $1.16\{0.44\}$ & $12.02\{1.00\}$ & $19.32\{1.00\}$ & $1.80\{0.59\}$ & $40.71\{1.00\}$ & $10.23\{0.99\}$ & $0.65\{0.28\}$ & $0.88\{0.36\}$ \\
\hline
\end{tabular}

Notes: See notes to Table $2 \mathrm{a}$. 

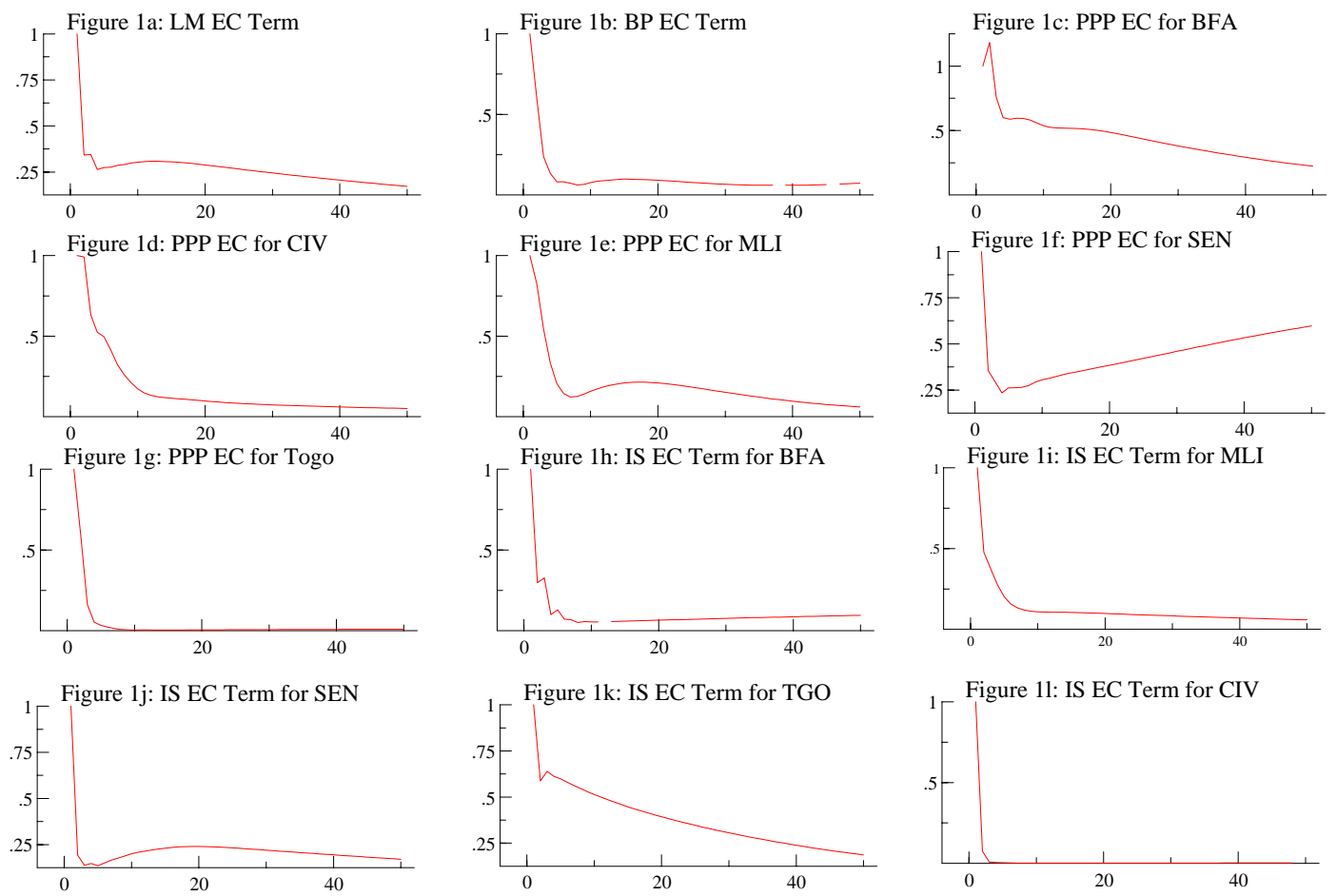

Figure 1: Persistence Profiles of the Long Run Relations to the Respective Unit Shocks. 

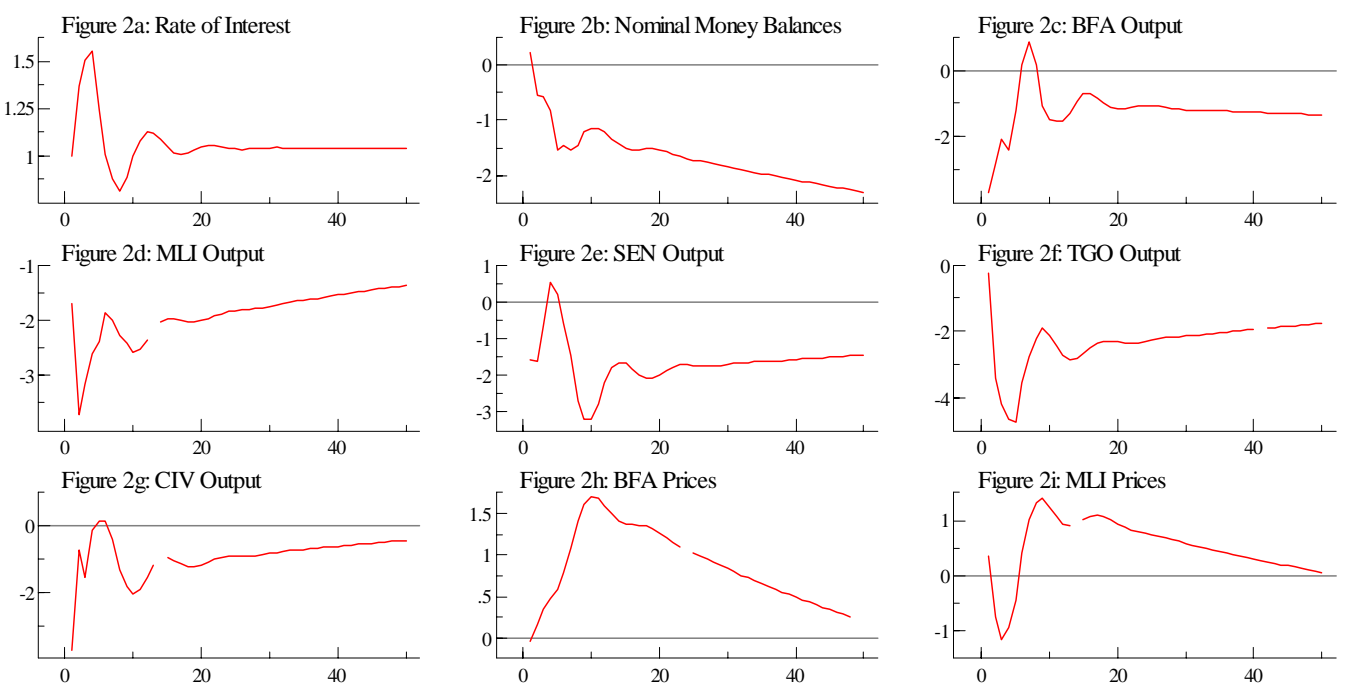

Figure 2i: MLI Prices
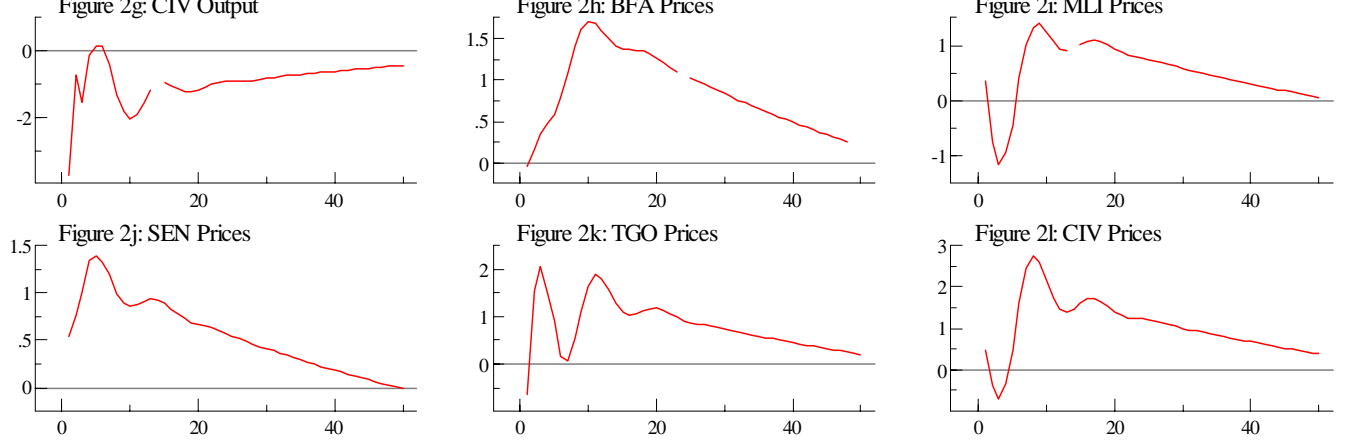

Figure 2: Impulse Responses to a Unit Monetary Shock 


\section{University Library}

\section{- M M N E R VA A gateway to Melbourne's research publications}

Minerva Access is the Institutional Repository of The University of Melbourne

Author/s:

Fielding, D;Lee, K;Shields, K

Title:

Does one size fit all? Modelling macroeconomic linkages in the West African Economic and Monetary Union

Date:

2012-02-01

Citation:

Fielding, D., Lee, K. \& Shields, K. (2012). Does one size fit all? Modelling macroeconomic linkages in the West African Economic and Monetary Union. ECONOMIC CHANGE AND RESTRUCTURING, 45 (1-2), pp.45-70. https://doi.org/10.1007/s10644-011-9109-9.

Persistent Link:

http://hdl.handle.net/11343/283135 